NBER WORKING PAPER SERIES

\title{
THE CONSUMPTION VALUE OF COLLEGE
}

\author{
Yifan Gong \\ Lance Lochner \\ Ralph Stinebrickner \\ Todd R. Stinebrickner \\ Working Paper 26335 \\ http://www.nber.org/papers/w26335 \\ NATIONAL BUREAU OF ECONOMIC RESEARCH \\ 1050 Massachusetts Avenue \\ Cambridge, MA 02138 \\ October 2019, Revised January 2021
}

We thank Tom Crossley and participants at several conferences for their valuable suggestions and comments. We also thank Kevin Stange for providing data from Jacob, McCall, and Stange (2018) on amenity measures for US colleges. The project was made possible by generous funding from The Mellon Foundation, The Spencer Foundation, The National Science Foundation, and The Social Sciences and Humanities Research Council. Lochner acknowledges generous support from Social Sciences and Humanities Research Council of Canada for this research. Lochner has no other relevant or material financial interests that relate to the research described in this paper. The views expressed herein are those of the authors and do not necessarily reflect the views of the National Bureau of Economic Research.

NBER working papers are circulated for discussion and comment purposes. They have not been peer-reviewed or been subject to the review by the NBER Board of Directors that accompanies official NBER publications.

(C) 2019 by Yifan Gong, Lance Lochner, Ralph Stinebrickner, and Todd R. Stinebrickner. All rights reserved. Short sections of text, not to exceed two paragraphs, may be quoted without explicit permission provided that full credit, including () notice, is given to the source. 
The Consumption Value of College

Yifan Gong, Lance Lochner, Ralph Stinebrickner, and Todd R. Stinebrickner

NBER Working Paper No. 26335

October 2019, Revised January 2021

JEL No. I20,I21,I23,I26,I28

\section{$\underline{\text { ABSTRACT }}$}

This paper uses the Euler equation and novel data from Berea College students on their consumption expenditures during and after college, desired borrowing amounts, beliefs about post-college earnings, and elicited risk-aversion and time preference parameters to determine their consumption value of college attendance. Estimates suggest an average annual consumption value of college as high as $\$ 15,110$ with considerable heterogeneity across students. Accounting for these benefits raises the average expected return to college by as much as $18 \%$ and substantially lowers the estimated willingness-to-pay for higher student loan limits.

Yifan Gong

Social Science Centre

The University of Western Ontario

London, ON

Canada

ygong48@uwo.ca

Lance Lochner

Department of Economics

Faculty of Social Science

Western University

1151 Richmond Street, North

London, ON N6A 5C2

CANADA

and NBER

llochner@uwo.ca

\author{
Ralph Stinebrickner \\ Berea College \\ Berea, KY 40403 \\ and University of Western Ontario \\ ralph_stinebrickner@berea.edu
}

Todd R. Stinebrickner

Department of Economics

The University of Western Ontario

London, Ontario, N6A 5C2

CANADA

and NBER

trstineb@uwo.ca 


\section{Introduction}

A growing number of studies estimate that factors beyond traditionally measured costs (tuition and foregone earnings) and earnings benefits of education play an important role in college attendance and field-of-study decisions. These factors are often referred to as "psychic", "utility", or "consumption" costs/benefits of schooling, yet there is little, if any, direct evidence on their nature or values. Instead, these factors are generally unobserved with their values typically inferred from choices that deviate from what is expected based on measured costs and returns (e.g., someone who attends college despite negative predicted net returns is estimated to have a positive "psychic/utility/consumption" value of college). Commonly observed differences in behavior among individuals with the same measured costs and returns are further taken to imply considerable heterogeneity in these factors. ${ }^{1}$

By measuring the amenities provided by institutions, Jacob, McCall, and Stange (2018) provide some of the most direct evidence suggesting a non-trivial consumption value of college attendance. They show that, on average, colleges spend about half as much on amenities as on academics and that these amenities influence students' decisions about which college to attend. The goal of Jacob, McCall, and Stange (2018) is to provide marginal valuations of spending on amenities, not to provide a measure of the total consumption value of college. However, insights in their paper help highlight two key difficulties that would arise in attempts to identify the consumption value using approaches that directly measure specific activities, perks, or benefits valued by college students: (i) disentangling consumption from human capital benefits can be difficult because, as they note, amenities may influence choices, in part, by improving the earnings prospects of students. ${ }^{2}$ and (ii) capturing all consumption benefits can be difficult both because many recognized amenities may be difficult to measure and because consumption benefits may arise in ways that are hard to recognize or describe.

This paper takes a very different approach and represents the first attempt to quantify all consumption benefits of college that are directly substitutable with other goods, services,

\footnotetext{
${ }^{1}$ Lazear (1977) provides an early analysis of the consumption vs. investment value of education. See, e.g., Keane and Wolpin (1997, 2001), Cunha, Heckman, and Navarro (2005), Heckman, Lochner, and Todd (2006), Abbott et al. (2019), and Guo and Leung (2020) for estimates of the importance of "psychic/utility/consumption" factors in explaining schooling attendance decisions. See, e.g., Arcidiacono (2004), Rask (2010), Zafar (2013), Gemici and Wiswall (2014), and Wiswall and Zafar (2015) for evidence on the importance of tastes in college major decisions.

${ }^{2}$ Several expenditure categories in their amenity measure could improve post-schooling earnings, including spending on student activities, student organizations, student health services, cultural events, etc.
} 
and activities that students would otherwise purchase. For example, students have easy access to athletic and entertainment facilities on campus. They may also have many free or inexpensive leisure and entertainment opportunities available to them that are unavailable (or much less attractive) to non-students. A quintessential example involves playing frisbee with friends on the campus quad. Students may benefit greatly from such opportunities, allowing them to achieve high levels of effective consumption with much lower levels of actual expenditures. We refer to the "consumption value" of college as the difference between effective consumption and measured consumption expenditures.

It is important to quantify these consumption benefits of college for at least two reasons. First, a large consumption value of college would lead to low levels of observed consumption expenditures during school, which could easily be misinterpreted as evidence of binding credit constraints. ${ }^{3}$ In this case, policymakers might overstate the amounts students need to borrow in order to smooth (effective) consumption during and after college. Second, the "consumption value" of college may be an important factor determining the total return to college, so that a failure to incorporate it could lead to an under-valuation of post-secondary education. This has been highlighted by the current pandemic, where the movement to distance or online learning appears to have made college less attractive for many (potential) students. ${ }^{4}$ For example, in a recent New York Times article (May 19, 2020), Hartocollis (2020) discusses the manner in which the University of Kentucky should re-open for the fall of 2020, noting that "For many students, part of the joy of college is playing Frisbee in the grass, studying over shared boxes of pizza, ..., drinking at town bars."

We take an innovative approach made possible by unique data from the Berea Panel Study (BPS), which follows students from Berea College in central Kentucky. While Berea College is unique in one important respect discussed below, it is otherwise quite typical of most small, high quality liberal arts institutions scattered throughout the U.S. We exploit BPS data to identify individual-specific consumption values of college based on the Euler equation for consumption during and after college. Under perfect credit markets, individuals should equate the marginal utility of consumption during college with the (discounted)

\footnotetext{
${ }^{3}$ Many studies exploit measures of assets during and/or after school to identify borrowing limits and the role of borrowing constraints (e.g., Keane and Wolpin, 2001; Johnson, 2013; Hai and Heckman, 2017). This implicitly assumes that consumption expenditures reflect total effective consumption, thereby ignoring the "consumption" benefits of college we study.

${ }^{4}$ Note, however, that shifts in demand for college related to the unexpected shift to distance learning would not necessarily identify the consumption value of college, because distance learning also has direct effects on educational (academic) quality.
} 
expected marginal utility of consumption in future periods. Thus, a comparison of observed consumption expenditures during college to the amount that students (expect to) spend on consumption after college would be directly informative about the consumption value of college. Intuitively, if individuals desire smooth consumption profiles, a large jump in consumption expenditures upon leaving college would likely indicate a sizable consumption value of college.

Two important challenges arise due to credit market frictions. First, limited borrowing opportunities during school could lead to a jump in consumption spending after college when individuals begin to receive higher earnings. We address this concern using a BPS survey question that identifies whether individuals are currently credit constrained, and if so, how much they would choose to borrow if the constraint were eliminated. This allows us to identify desired consumption expenditures (during college) for everyone in our sample, regardless of whether they are borrowing constrained.

Second, when students face uninsurable post-college earnings risk, a jump in consumption spending after college could also reflect the resolution of that risk and a reduction in precautionary savings motives. To address this concern, it is necessary to characterize, for each student, the distribution describing beliefs about post-college consumption. Our approach to this issue involves two primary tasks. First, we characterize beliefs about future earnings using direct survey questions in the BPS that elicit these beliefs during college. Second, we determine the post-college consumption function that maps these beliefs about future earnings into beliefs about future consumption.

We take two very different approaches for computing post-college consumption functions (i.e., the second task). Our first approach, which we refer to as the Data-Driven (DD) Approach, exploits post-college data on actual earnings, consumption, and debt to directly estimate this consumption function. This approach is appealing due to its simplicity; however, it implicitly assumes that students are ex ante homogeneous in terms of preferences and post-college beliefs about career earnings trajectories (conditional on earnings and debt at the end of college). ${ }^{5}$ Our second approach relaxes this homogeneity assumption, instead solving for individual-specific post-college consumption functions based on a canonical lifecycle consumption/saving problem. We refer to this approach as the Model-Based (MB)

\footnotetext{
${ }^{5}$ It is straightforward to allow for observable heterogeneity in these respects; however, we find very little heterogeneity in estimated consumption functions based on observable factors like gender, race, high school grades, and parental income.
} 
Approach.

Given the critical importance of the two tasks involved in characterizing the distribution describing beliefs about future consumption, we thoroughly examine the robustness of our results to alternative assumptions related to these tasks. Most importantly, because the marginal utility of consumption is very high at low levels of consumption, we explore alternative assumptions regarding beliefs about potential low-income realizations after school and, in the MB Approach, about post-college borrowing opportunities. We also explore concerns about the role of durable goods purchases after college, as well as potential jumps in consumption expenditures related to marriage. In all cases, average implied consumption values are similar to our baseline estimates.

The rich set of information collected in the BPS also enables us to consider (and, in some cases, dismiss) several other economic forces that might explain jumps in consumption upon college graduation. First, debt-averse students may not wish to borrow more despite low levels of in-school consumption. We sidestep this concern by focusing on the majority of students that show no indication of debt-aversion when explaining why they prefer not to borrow more when in school; although, estimates are similar when including these students in our analysis. Second, Aguiar and Hurst (2005, 2007) show that, by devoting more time to home production and shopping, older individuals are able to maintain high levels of effective consumption despite reduced expenditures. Since the combined amount of time Berea students spend studying and working is similar to the amount of time they spend working after school (Stinebrickner and Stinebrickner, 2003, 2008a; Stinebrickner, Stinebrickner, and Sullivan, 2019), a similar phenomenon is unlikely to explain important changes in consumption upon graduation for our sample. Third, one might worry that there are fewer consumption opportunities in the city of Berea than wherever graduates move after college, which could lead to lower "market-constrained" consumption expenditures while in school. We show in Section 2, however, that Berea's population density is similar to that of the cities its students live in two years after graduation, suggesting that local offerings are unlikely to improve after leaving school. ${ }^{6}$

Our empirical results suggest that a substantial consumption value of college exists among

\footnotetext{
${ }^{6}$ Indeed, the presence of Berea College and its many students likely means that Berea offers more goods and services valued by students compared to similarly sized areas without a post-secondary institution. The fact that roughly $80 \%$ of students report in the BPS that they enjoy their life in school more than if they were not enrolled further suggests that low levels of in-school consumption are not driven by a lack of consumption opportunities. We explore differential prices for goods/services during and after school in Section 6.5.
} 
Berea students. Based on our main specifications, the average annual consumption value ranges from about $\$ 12,000$ to about $\$ 15,000$, depending on the approach used to map the distribution describing beliefs about post-college earnings into the distribution describing beliefs about post-college consumption. The average annual consumption value is quite robust to alternative assumptions, with none of our assumptions yielding a value below $\$ 9,000 /$ year. These sizable benefits are consistent with other survey responses in which the vast majority of Berea freshman indicate that they enjoy college more than they think they would enjoy not being in college. Incorporating these additional consumption benefits of college increases average rates of return to college by $14-18 \%$ and substantially reduces the measured value of increasing student loan limits. Despite the fact that we examine students attending the same institution, we document considerable heterogeneity in the consumption value across students, little of which is explained by observable differences in gender, race, family income, or high school grades.

The rest of this paper proceeds as follows. In Section 2, we discuss key conceptual issues and corresponding data requirements for quantifying the consumption value of college. Data from the Berea Panel Study (BPS) are discussed in Section 3, while Sections 4 and 5 develop and implement our DD and MB Approaches, reporting our baseline estimates of the distribution of college consumption values for Berea College students. These sections also explore the robustness of our results to several important alternative assumptions and data treatments. In Section 6, we study several additional issues, including heterogeneity in college consumption values across students from different backgrounds and the implications of a sizable consumption value for estimated returns to college and for evaluating the benefits from increasing student borrowing opportunities. We also explore two alternative forms of college consumption benefits, first estimating benefits that are only substitutable with non-housing goods/services and then exploring whether college students receive discounted prices on consumption goods/services along with "free" benefits. Section 7 concludes with a summary of key results and the broader lessons from our approach and empirical findings.

\section{Measuring the Consumption Value of College}

Our general approach to measuring the consumption value of college is based on the Euler equation that equates the marginal utility of consumption during college with the discounted expected marginal utility of consumption after leaving school. Suppose students attend 
college for $G$ years and let $U\left(C_{t}\right)$ (with $U^{\prime}(\cdot)>0, U^{\prime \prime}(\cdot)<0$ ) reflect utility from "effective consumption" $C_{t}$ each period, $\beta>0$ the rate of time preference, and $r>0$ the market interest rate. Then, the Euler equation linking consumption during the first year of college with consumption behavior after leaving college $G$ years later (in the absence of borrowing constraints) is

$$
U^{\prime}\left(C_{1}\right)=[\beta(1+r)]^{G} E_{1}\left[U^{\prime}\left(C_{G+1}\right)\right],
$$

where $E_{1}[\cdot]$ reflects expectations conditional on information available and beliefs at year $t=1$, the first year of college. ${ }^{7}$

While enrolled in college, we assume that "effective consumption" $C_{t}$ reflects the sum of consumption expenditures $C_{t}^{e x}$ and any additional "consumption value of college", $\mathcal{V}$ :

$$
C_{t}=C_{t}^{e x}+\mathcal{V} \quad \text { for all } t=1, \ldots, G
$$

This assumes that the consumption value $\mathcal{V}$ enters in a "lump sum" fashion, capturing all benefits that are direct substitutes of purchased consumption goods and services. For example, having access to various on-campus entertainment opportunities can reduce a student's willingness to pay for movie and concert tickets; hence, its value is captured by $\mathcal{V}$. Similarly, any "psychic benefits" of college are reflected in $\mathcal{V}$ to the extent that they reduce the demand for consumption goods/services. ${ }^{8}$ In Section 6.5, we examine whether college also provides goods/services at a discounted price.

Once individuals leave school, we assume that effective consumption is fully reflected in expenditures (i.e., $C_{t}=C_{t}^{e x}$ for all $t \geq G+1$ ). However, our estimates represent an informative lower bound on the consumption value if, after leaving school, individuals benefit from free non-market amenities provided by, for example, municipalities or their employers. ${ }^{9}$ We explicitly address the possibility that individuals who live with family after leaving school may benefit from significant in-kind transfers.

\footnotetext{
${ }^{7}$ Our focus on the first year of college allows us to identify consumption values for all attendees, while considering later years of school would limit the sample to those who have not yet dropped out. Appendix H.6 shows that our results are very similar when replicating the analysis using data from the second year of college (along with the first year after college).

${ }^{8}$ Our estimates of $\mathcal{V}$ do not capture any benefits that are fully separable from other consumption goods/services. For example, individuals may feel pride in attending college, which may have no effect on their demand for traditional consumption goods/services.

${ }^{9}$ For example, individuals may have access to public parks or events organized by local municipalities; employers may also provide valuable amenities that substitute for goods and services individuals might otherwise purchase. In both cases, reported post-college consumption expenditures would understate effective post-college consumption, in which case our approach would under-estimate $\mathcal{V}$.
} 
A natural approach for estimating $\mathcal{V}$ exploits the Euler equation (1). Substituting for consumption using equation (2) into the Euler equation and re-arranging terms yields:

$$
\mathcal{V}=U^{\prime-1}\left([\beta(1+r)]^{G} E_{1}\left[U^{\prime}\left(C_{G+1}\right)\right]\right)-C_{1}^{e x},
$$

where $U^{\prime-1}(\cdot)$ is the inverse function for marginal utility. Notice that $\mathcal{V}$ is decreasing in observed consumption expenditures during college, $C_{1}^{e x}$, and in the expected marginal utility of post-college consumption, $E_{1}\left[U^{\prime}\left(C_{G+1}\right)\right]$. The latter implies that for any given expenditure level during college, $\mathcal{V}$ is increasing in the average level of post-college consumption and decreasing in its variance. It is also well-known that the left tail of the distribution for postcollege consumption is particularly important for $E_{1}\left[U^{\prime}\left(C_{G+1}\right)\right]$, since the marginal utility of consumption at very low levels is quite high. ${ }^{10}$ We devote considerable attention to this issue below.

Our Euler equation approach presents two main challenges. The first challenge is one of data availability: equation (3) requires information about preferences $(\beta$ and $U(\cdot))$, consumption expenditures during college $\left(C_{1}^{e x}\right)$, and the full distribution describing beliefs (while in college) about post-college consumption. We address this challenge through a combination of rich data and economic modeling.

The second challenge is conceptual: equations (1) and (3) only hold in the absence of binding borrowing constraints. When some students are borrowing constrained, as suggested by much of the literature (Lochner and Monge-Naranjo, 2012), it is impossible to distinguish between binding constraints and a positive consumption value of college using only information on preferences and consumption behavior. We address this critical problem using a novel survey question that identifies whether students are borrowing constrained during college and the amount that constrained students would like to borrow if they could. ${ }^{11}$

Let $\hat{\delta} \geq 0$ reflect the amount of additional resources a student would like to borrow during college, to be repaid after leaving college. Notice $\hat{\delta}>0$ for those that are constrained, while $\hat{\delta}=0$ for those that are not. Letting $\hat{C}_{G+1}$ reflect "optimal" post-college consumption in the hypothetical borrowing scenario (described in Section 3.3), equation (3) can be modified to

\footnotetext{
${ }^{10}$ Under standard Inada conditions and for the utility function we employ empirically, $\lim _{C \rightarrow 0} U^{\prime}(C)=\infty$.

${ }^{11} \mathrm{~A}$ very similar problem arises if individuals are debt-averse, in which case the Euler equation need not hold with equality even for individuals who do not wish to borrow. Although we are able to identify these students from the survey, we are unable to determine how much these students would like to borrow if they were not debt-averse. As a result, we limit our analysis to those students that are not debt-averse. We discuss this and a few other challenges (e.g., lumpy expenditures on durable goods) further below.
} 
account for constrained students wishing to borrow $\hat{\delta}$ :

$$
\mathcal{V}=U^{\prime-1}\left([\beta(1+r)]^{G} E_{1}\left[U^{\prime}\left(\hat{C}_{G+1}\right)\right]\right)-C_{1}^{e x}-\hat{\delta} .
$$

When students are unconstrained, $\hat{\delta}=0$ and $\hat{C}_{G+1}=C_{G+1}$, so equation (4) reduces to equation (3).

Our data contain direct survey measures of $C_{1}^{e x}$ and $\hat{\delta}$. We assume that preferences have the standard CRRA form:

$$
U(C)=\frac{C^{1-\rho}}{1-\rho}, \quad \rho>0,
$$

and use a battery of BPS survey questions about risk and intertemporal tradeoffs to obtain estimates of relative risk aversion $\rho$ and time preference $\beta$ for each respondent.

Assuming that $r$ is known (we assume $r=0.05$ ), the only remaining unknown in equation (4) is the expected marginal utility of post-college consumption, $E_{1}\left[U^{\prime}\left(\hat{C}_{G+1}\right)\right]$, which requires knowledge of the distribution describing beliefs about $\hat{C}_{G+1}$. Although the BPS does not directly elicit this distribution, it does contain measures of student debt and beliefs about post-college earnings. We now show how, together, these can be used to characterize the (subjective) distribution of $\hat{C}_{G+1}$ and, therefore, $E_{1}\left[U^{\prime}\left(\hat{C}_{G+1}\right)\right] .{ }^{12}$

Note that post-college consumption, $C_{G+1}=\tilde{C}\left(D_{G+1}, W_{G+1}\right)$, is a function of observed post-college debt $D_{G+1}$ and earnings $W_{G+1} \cdot{ }^{13}$ Given the modest values for $\hat{\delta}$ in our sample, we assume that students' post-school earnings would be unaffected by borrowing this additional amount. As such, additional (hypothetical) debt $\hat{\delta}$ should affect future consumption in the same way as does existing debt. Under this assumption and CRRA preferences, this implies that

$$
\mathcal{V}=\left([\beta(1+r)]^{G} E_{1}\left[\tilde{C}\left(D_{G+1}+(1+r)^{G} \hat{\delta}, W_{G+1}\right)^{-\rho}\right]\right)^{-1 / \rho}-C_{1}^{e x}-\hat{\delta} .
$$

Assuming that $D_{G+1}$ is fully anticipated when students enter college, expectations need only be taken over post-college earnings possibilities. ${ }^{14}$ To that end, subjective belief distributions about post-college earnings, elicited as part of the BPS during college, can be used.

\footnotetext{
${ }^{12}$ If unconstrained students all faced the same distribution of post-college consumption and held rational expectations about future consumption, then we could estimate $E_{1}\left[U^{\prime}\left(\hat{C}_{G+1}\right)\right]$ for those (unconstrained) students using the distribution of their observed post-college consumption. As documented in Section 3 , first-year students are quite optimistic about their future earnings, raising concerns about this approach.

${ }^{13}$ This consumption function also (implicitly) depends on credit market frictions, preferences, and beliefs about subsequent post-college earnings (conditional on $D_{G+1}$ and $W_{G+1}$ ), all of which could vary across individuals.

${ }^{14}$ Known $D_{G+1}$ is consistent with students reporting that over $80 \%$ of end-of-college debt (in our sample) was borrowed to cover college-related expenditures, which are likely anticipated early in college.
} 
We must also characterize the post-college consumption function, $\tilde{C}(\cdot, \cdot)$. We develop and implement two different approaches. First, we take a data-driven approach under the assumption that all students have the same post-college consumption function $\tilde{C}(\cdot, \cdot) .{ }^{15}$ For this approach, we flexibly estimate this function using survey data on $C_{G+1}, D_{G+1}$, and $W_{G+1}$. Second, we take a model-based approach in which the consumption function is obtained as the solution to a standard lifecycle consumption allocation problem under uncertainty and limited borrowing opportunities. ${ }^{16}$ Sections 4 and 5 describe these approaches in greater detail and provide estimated distributions of $\mathcal{V}$ for students at Berea College using both approaches.

\section{Berea College, Data, and Descriptive Statistics}

\subsection{Berea College and the Berea Panel Study (BPS)}

Our empirical analysis is based on the Berea Panel Study (BPS) conducted by Todd and Ralph Stinebrickner. It is a longitudinal survey that follows two cohorts of students at Berea College from the time they entered college, in 2000 and 2001, until 2014. Students were surveyed multiple times each year while in college, with the baseline survey taking place immediately after students arrived for their freshman year. Post-college surveys were conducted annually.

Berea College is a four-year liberal arts school located in central Kentucky. As discussed previously (Stinebrickner and Stinebrickner, 2003), the school focuses on providing educational opportunities to students from relatively low-income backgrounds, and as part of this focus, offers full-tuition scholarships to all students. Despite this unique feature, Berea offers a standard liberal arts curriculum, and its students are similar in academic quality to students at nearby University of Kentucky (Stinebrickner and Stinebrickner, 2008b). Additionally, Berea's campus is similar to that of other quality liberal arts colleges. Consistent with recent trends (Jacob, McCall, and Stange, 2018), Berea constructed a 10.5 million dollar recreational/wellness center, built a new dorm, and entirely re-vamped its dining fa-

\footnotetext{
${ }^{15}$ This would be the case if individuals faced identical credit markets and were homogeneous in their preferences and beliefs about future earnings conditional on period $G+1$ earnings and debt. Note that it is straightforward to allow for observed heterogeneity (e.g., by conditioning the entire problem on observed student characteristics); however, our sample size is modest and efforts to do so were not particularly enlightening. Our second approach incorporates very flexible heterogeneity; yet, finds only modest differences in $\mathcal{V}$ based on observable characteristics.

${ }^{16}$ See Browning and Crossley (2001) for a survey on lifecycle models of consumption allocation.
} 
cilities within the last two decades. Based on the IPEDS data used by Jacob, McCall, and Stange (2018), Berea College's per student expenditures on student amenities in 2004 were at roughly the 65th percentile among U.S. private bachelor's degree-granting institutions. Aside from fully subsidized tuition, Berea is similar to most other small, private liberal arts institutions in the U.S.

With a population of approximately 10,000, the city of Berea has a similar population density to the places its students move to after leaving (specifically, its population is at the 40th percentile based on zip code of residence 2 years after finishing). This suggests that the availability of various consumption goods and local amenities, aside from additional offerings associated with living in a "college town", is likely to be quite similar to that faced by students after they graduate.

\subsection{Overview of BPS Surveys and Key Variables}

We begin our data description with a brief overview of the BPS surveys used to create key variables for our analysis. The next subsection provides greater details on these variables and the main samples we use. For reasons discussed below, our analysis focuses only on the cohort of students who matriculated in 2001.

Baseline (College Entry) Survey: The baseline survey was completed by 375 (out of 434) students immediately after they entered Berea College in 2001. It elicited beliefs about each student's own (subjective) distribution of post-college earnings and administered a battery of questions designed to identify person-specific measures of risk aversion, $\rho$, and time preference, $\beta$. Administrative data on standard background information (e.g., gender, race, high school grades, family income) were also merged with survey records for each student.

Second Semester Survey: The second survey we use was administered at the beginning of the second semester. Roughly $9 \%$ of Berea freshman had dropped out by the time of this survey, which collected information from 327 respondents about their consumption expenditures during the first year of college (used to determine $C_{1}^{e x}$ ) and information about desired borrowing used to determine $\hat{\delta}$ and whether students are debt-averse. 
End-of-College Survey: Students were surveyed at the end of their college careers. With a cumulative drop out rate of nearly $50 \%$, these surveys collected information about end-ofcollege savings, college loans, credit debt, and other loans from 195 students. These responses are combined to create our measure of end-of-college debt, $D_{G+1}$.

Post-College Survey: The last major survey we use was administered to 247 students during the first year after graduation (2006 or 2007). It collected information on postcollege consumption, $C_{G+1}$, and earnings, $W_{G+1}$. The sample size for the post-college survey is somewhat larger than the sample size for the end-of-college survey, in part, because participation on the baseline survey was a necessary condition for subsequent in-school survey participation, but not for post-college survey participation.

\subsection{First-Year Measures of Consumption, Desired Borrowing, and Beliefs}

The BPS baseline survey asks students to report the value of all expenditures (other than room and board charges and spending on textbooks) during the first year of college, which we denote $C_{1}^{\text {oth }}$. The value of room and board for the academic year at Berea is $\$ 4,760$ (in 2001 dollars), which is quite similar to that of comparable four-year colleges in the Appalachian region of Kentucky. ${ }^{17}$ We further assume that the quality of food and housing that students receive in-kind from parents during the three-month summer break is similar to the quality of accommodations received at Berea during the school year. We, therefore, inflate Berea's room and board costs by the factor $12 / 9$ to obtain a total annual value for food and housing of $C^{f h}=\$ 6,350 .{ }^{18}$ Total expenditures during the first year of college are $C_{1}^{e x}=C_{1}^{o t h}+C^{f h}$.

Crucial for identification of $\mathcal{V}$, the BPS contains a unique question that characterizes students' preferred additional borrowing - and, therefore, the presence of borrowing constraints — while in school. Our main analysis uses the 2001 cohort of students who answered

\footnotetext{
${ }^{17}$ Based on figures from the US News \& World Report Best Colleges listing (www.usnews.com/bestcolleges), average room and board charges amount to $\$ 5,800$ for the following set of institutions: Berea College, Alice Lloyd College, Eastern Kentucky University, Morehead State University, Union College, University of Pikeville, and University of the Cumberlands. This average is based on amounts for academic years 2017-18 or 2018-19, adjusted for inflation to 2001 dollars using the CPI.

${ }^{18}$ This amount is quite similar to average per-person expenditures on food and housing for households with a 22-29 year old college graduate living (in the South) with his/her parents. See Appendix A.1.
} 
the following question during the baseline survey: ${ }^{19}$

- Suppose that someone offered to loan you money this year so that you could increase the amount of money that you would have for spending money during this year. Suppose that the loan is made at a fair interest rate and that you would not have to begin repaying the loan until after you leave Berea.

Q.1 Would you accept the loan? YES NO

\section{- Q.1.A If you answered YES,}

You would like to borrow money to increase your spending at Berea during this year. Remember, you will have to pay back the loan and any interest after leaving Berea. How much money would you choose to borrow this year in order to increase your spending money this year? \$

- Q.1.B If you answered NO, please check any that apply. Why would you not accept the loan? Please check any of the following that apply.

1. I am happy with the amount I am currently spending and would not choose to increase spending now because I would have less to spend later when I had to repay the loan and interest.

2. Even though I would prefer to spend more now and less later, I would not feel comfortable accepting a loan.

3. Other (please explain)

We set $\hat{\delta}=0$ for students who would not accept a loan and set $\hat{\delta}$ to the desired amount reported in Q.1.A for those who would. ${ }^{20}$ In considering the quality of survey responses to this question, it is noteworthy that students are being asked to consider choices — whether and how much to borrow — that should be quite salient to them. ${ }^{21}$ Indeed, as discussed

\footnotetext{
${ }^{19}$ We do not study students from the 2000 cohort, because Q.1.A was not asked of them until their third year of college. As discussed in Appendix H.6, we obtain similar results when replicating our analysis for students from the 2001 cohort using data from their second (rather than first) year in college, since question Q.1 and other questions related to consumption and beliefs about post-college earnings are also available in this year.

${ }^{20}$ Given that, on average, students believe the probability of graduating is greater than $80 \%$, we assume that leaving Berea is equivalent to spending $G=4$ years in college.

${ }^{21}$ In their study of the importance of credit constraints, Stinebrickner and Stinebrickner (2008b) show that this question is predictive of college dropout, even when conditioning on observed characteristics like race and high school grades. Crossley and Low (2014) exhibit the usefulness of a similar survey question that was administered to characterize whether young workers would like to borrow.
} 
later in this section, roughly four-fifths of Berea students borrow during school, with these students accumulating an average of over $\$ 5,500$ during their college careers.

Answers to question Q.1.B are also useful for our analysis. We identify students as "debtaverse" if any of their responses indicate that they would reject a loan for a reason other than consumption smoothing (e.g., answer '2' or similar written responses).

A separate battery of questions elicits students' beliefs about the distribution of future period $t$ earnings, $F_{1}^{W_{t}}$, asked during the first year of college. Students were asked about three specific future periods $(1,6$, and 16 years after graduation), which we use to determine belief distributions about earnings over students' future post-college careers. Given the importance of beliefs about the possibility of low earnings realizations (for the expected marginal utility of post-college consumption), it is noteworthy that the preamble to these questions explicitly asked respondents to take into account "...the possibility that [they would] work part-time, the possibility that [they would] not be working at all, and the possibility that [they would] attend graduate school."

Students were asked to report the minimum $\left(\underline{W}_{1, t}\right)$ and three quartiles $\left(Q_{1, t}^{k}\right.$, for $k=$ $1,2,3)$ of their belief distributions. Assuming that $F_{1}^{W_{t}}$ is a shifted log-normal distribution, i.e., $\log \left(W_{t}-\underline{W}_{1, t}\right) \sim N\left(\mu_{1, t}, \sigma_{1, t}^{2}\right)$, we identify individual-specific distribution parameters:

$$
\mu_{1, t}=\log \left(Q_{1, t}^{2}-\underline{W}_{1, t}\right) \quad \text { and } \quad \sigma_{1, t}=\log \left(\left[\frac{Q_{1, t}^{3}-\underline{W}_{1, t}}{Q_{1, t}^{1}-\underline{W}_{1, t}}\right]\right) /[\Phi(0.75)-\Phi(0.25)],
$$

where $\Phi(\cdot)$ is the standard normal cumulative distribution function (CDF). After dropping 26 students who reported invalid (i.e., non-response, non-increasing quartile values) or extreme (expected maximum earnings over $\$ 1$ million) responses, we are left with 349 students with measured belief distributions given by $\left(\underline{W}_{1, t}, \mu_{1, t}, \sigma_{1, t}\right)$.

Overall, there are 300 students from the 2001 cohort for whom we have valid measures of consumption expenditures $C_{1}^{e x}$, desired borrowing $\hat{\delta}$, and subjective beliefs about postcollege earnings $F_{1}^{W_{t}}$. Because the Euler equation underlying our approach abstracts from debt-aversion, our main in-school sample includes 177 first-year students deemed not to be debt-averse based on their answer to question Q.1.B. We estimate $\mathcal{V}$ for these students; however, our conclusions are very similar when including those that would not borrow due to debt-aversion (see Appendix H.1).

Table 1 summarizes our measures of college consumption, desired borrowing, and beliefs about post-college earnings elicited during the first year of college for our main in-school 
sample. ${ }^{22}$ On average, students at Berea College spend only $\$ 910 /$ year on consumption goods and services, in addition to Berea's room and board charges and textbook purchases. More than two-thirds report that they would not like to borrow more $(\hat{\delta}=0)$, while the rest report average desired additional borrowing, $\hat{\delta}$, of $\$ 890$. Combining these figures with $C^{f h}$, average preferred annual consumption expenditure during college $\left(C_{1}^{e x}+\hat{\delta}\right)$ is $\$ 7,560$. The median of individual-specific subjective earnings distributions for the first year out of school $\left(Q_{1, G+1}^{2}\right)$ has a sample average of $\$ 43,620$, while the reported minimum value $\left(\underline{W}_{1, G+1}\right)$ has a sample average of $\$ 28,890$. On average, students expect to earn much more after school than they spend when in school; however, there is considerable heterogeneity in beliefs about post-college earnings, especially in comparison with the variation in college consumption expenditures.

Table 1: First-Year Consumption, Desired Borrowing, and Beliefs in BPS

\begin{tabular}{lccccc}
\hline & $C_{1}^{\text {oth }}$ & $\hat{\delta}$ & $\hat{\delta}($ if $>0)$ & $Q_{1, G+1}^{2}($ Median $)$ & $\underline{W}_{1, G+1}(\operatorname{Min})$ \\
\hline Mean & 0.91 & 0.30 & 0.89 & 43.62 & 28.89 \\
Std. Dev. & 0.88 & 0.70 & 0.97 & 23.15 & 15.25 \\
Median & 0.60 & 0.00 & 0.50 & 40.00 & 30.00 \\
Interquart. Range & 0.60 & 0.30 & 0.70 & 20.00 & 16.00 \\
Sample Size & 177 & 177 & 60 & 177 & 177 \\
\hline
\end{tabular}

Notes: All values in thousands of year 2001 U.S. dollars. $C_{1}^{\text {oth }}$ represents reported annual consumption expenditures (excluding room, board, and textbooks) during the first year of college. $\hat{\delta}$ represents the amount of additional loan a student is willing to take in the hypothetical borrowing scenario during the first year of college. $Q_{1, G+1}^{2}$ and $\underline{W}_{1, G+1}$ are the median and minimum of reported subjective earnings distributions during the first year of college, respectively.

\subsection{Post-College Debt, Consumption, and Earnings}

The BPS also collects information on actual earnings, $W_{G+1}$, and consumption, $C_{G+1}$, during the first year after college. Unlike the in-school surveys, which only asked about total consumption expenditures, the post-college survey asked students to report expenditures on 10 distinct categories of goods/services, which we combine to create our measure of total post-college consumption $C_{G+1}$. (See Appendix Table 8 for the distribution of expenditures within each category.)

\footnotetext{
${ }^{22}$ All dollar amounts in the paper are reported in year 2001 dollars based on the CPI.
} 
A potentially important practical concern is that reported post-college consumption expenditures may understate effective post-college consumption if individuals receive transfers in-kind from parents or other family members. This concern is particularly relevant for food and housing consumption for those who live with family after graduation (Kaplan, 2012). To address this concern, we turn to the Consumer Expenditure Survey (CES) from 2003-2007, using it to estimate average annual food and housing expenditures for 22-29 year-old college graduates living with their parents (in the South) as a function of own and parental earnings (see Appendix A.1). We then use these estimates to impute post-college food and housing spending for Berea graduates who are living with their parents at $t=G+1$ and report less spending (than the CES value) on these categories. This adjusted measure of food and housing expenditures is used in the construction of our baseline measure of total post-college consumption, $C_{G+1} \cdot^{23}$

A second potential concern is that students may spend a lot on durable goods (e.g. a new car) during their first year out of college, in which case actual consumption flows may be (temporarily) over-stated. Taking advantage of our detailed categories of consumption expenditures, we show in Section 4.3 that this has little impact on our estimates of $\mathcal{V}$.

Student debt at the end of college, $D_{G+1}$, is obtained for 195 sample respondents. Among these students, $81 \%$ reported positive end-of-college debt, where net savings implies $D_{G+1}<0$. The average accumulated debt was $\$ 5,640$ with a standard deviation of $\$ 6,660$ and interquartile range of $\$ 7,750$. Our baseline analysis imputes missing values of post-college debt with this sample average; however, we show in Appendix H.2 that results are nearly identical when using observed demographic characteristics for a more sophisticated imputation.

Since the post-college consumption function $\tilde{C}\left(D_{G+1}, W_{G+1}\right)$ depends on current debt and earnings (and beliefs about future earnings in the MB Approach), we use a sample that is different than our main in-school sample when estimating this function. This sample is limited to graduates of Berea who reported positive post-college consumption, $C_{G+1}$, and earnings, $W_{G+1}$. Dropping those few recent graduates with children yields a sample of 194

\footnotetext{
${ }^{23}$ About one-third of students in our sample were living with their parents at $t=G+1$. Nearly all of these students (53/56) reported post-college food and housing consumption expenditures less than their predicted amounts based on estimates from the CES, which averaged $\$ 7,220$. In Section 4.3 , we consider a more conservative alternative that does not adjust reported post-college consumption in this way.
} 
Table 2: Post-College Debt, Consumption, and Earnings in BPS

\begin{tabular}{lccc}
\hline & $D_{G+1}$ & $C_{G+1}$ & $W_{G+1}$ \\
\hline Mean & 5.83 & 14.41 & 20.11 \\
Std. Dev. & 5.76 & 9.87 & 10.53 \\
Median & 5.64 & 12.68 & 18.68 \\
Interquart. Range & 4.60 & 7.79 & 13.17 \\
Sample Size & 151 & 151 & 151 \\
\hline
\end{tabular}

Notes: All values in thousands of year 2001 U.S. dollars. $D_{G+1}$ reflects end-of-college total debt. $C_{G+1}$ and $W_{G+1}$ are realized annual consumption and earnings in the first year after college, respectively.

graduates. ${ }^{24}$ Further excluding married respondents yields our main post-college sample of 151 unmarried, childless Berea graduates (with positive earnings and consumption). These additional family composition restrictions are imposed to avoid taking a stand on family consumption allocation decisions, since our main goal in estimating $\tilde{C}(\cdot, \cdot)$ is to determine how much students expect to consume (themselves) after college. However, we explore the robustness of our results to the inclusion of married graduates under an equal allocation rule.

Table 2 describes our data on post-college debt, consumption, and realized earnings for our main post-college sample. The average post-college debt for this sample is $\$ 5,830$ (about $\$ 200$ more than average post-college debt for the full sample of 195 respondents who reported $\left.D_{G+1}\right) .{ }^{25}$ During the first year after college, average consumption spending for these individuals was $\$ 14,410$ while actual earnings averaged $\$ 20,110$.

The much higher average post-college expenditures relative to (desired) spending during college ( $\$ 14,410$ vs. $\$ 7,560)$ is a strong indication that college provides considerable consumption benefits. ${ }^{26}$ Yet, this simple comparison neglects important concerns. On the one hand, uncertainty about post-school earnings could explain some of the rise in consumption. On the other hand, actual post-college earnings are substantially less than what students anticipated during their first year of college, consistent with the broader literature using ex-

\footnotetext{
${ }^{24}$ Because this sample is used to estimate post-college consumption behavior only, we do not eliminate students reporting debt-aversion during the first year of college. Thus, this sample is not a subset of our main in-school sample. To the extent that debt-aversion reduces post-college consumption (given debt and earnings levels), our estimated $\mathcal{V}$ will tend to be under-estimated.

${ }^{25}$ We impute $D_{G+1}$ for 33 (out of the 151) graduates in the main post-college sample who responded to the post-college survey but not the end-of-college survey.

${ }^{26}$ This large difference in consumption during and after college also exists when considering the 68 students in both the main in-school and post-college samples, which yields averages for $C_{1}^{e x}+\hat{\delta}$ and $C_{G+1}$ of $\$ 7,560$ and $\$ 13,730$, respectively.
} 
pectations data. ${ }^{27}$ This optimism suggests that a simple comparison of consumption during and after school may lead to an under-statement of the true consumption value of college. Fortunately, our approach explicitly accounts for both of these factors in estimating $\mathcal{V}$.

\subsection{Risk Aversion and Time Preference}

We utilize an approach based on Barsky et al. (1997) to estimate students' rate of time preference, $\beta$, and degree of risk aversion, $\rho$. We determine $\rho$ from a survey question that asks each person to compare the option of a risk-free wage with three options that all have a $50 \%$ chance of paying twice the risk-free wage and a $50 \%$ chance of paying either (1) one-half the risk-free wage, (2) two-thirds the risk-free wage, or (3) four-fifths the risk-free wage. For each person, the comparisons reveal whether $\rho$ falls in $(0,1],(1,2],(2,3.76]$, or $(3.76, \infty)$. For simplicity, our main analysis assigns values of $1,1.5,2.88$, and 3.76 to these four categories, respectively; although, Sections 4.3 and 5.4 show that our results are robust to other assumptions.

The estimation of time preference relies on a survey question about a student's preferred growth rate for consumption. Combined with knowledge of $\rho$, their choice identifies their discount rate $\beta$. Specifically, students are asked to choose from different lifecycle consumption profiles that vary in initial consumption and its growth rate $g_{C}$ such that they all yield the same (undiscounted) sum of total consumption. Assuming individuals choose the consumption profile to solve the following maximization problem:

$$
\max _{c t} \sum_{t} \beta^{t} \frac{c_{t}^{1-\rho}}{1-\rho} \quad \text { subject to } \quad \sum_{t} c_{t}=C,
$$

yields the Euler equation $\beta^{t+1} c_{t+1}^{-\rho}=\beta^{t} c_{t}^{-\rho}$, which directly identifies $\beta=\left(c_{t+1} / c_{t}\right)^{\rho}=g_{C}^{\rho}$. The BPS asks students to decide between six potential growth rates $(0.96,0.98,1.02,1.04$, and 1.06), which we use along with the value of $\rho$ from above to determine $\beta$ for each student. We obtain valid responses for both $\beta$ and $\rho$ for 363 students.

\footnotetext{
${ }^{27}$ Most directly related, Stinebrickner and Stinebrickner (2012) find that entering Berea students overestimated their future grade performance. Based on a national sample of Americans, Dominitz (1998) shows that although elicited earnings beliefs are predictive of earnings one year later, they are also consistently biased upwards. Hastings et al. (2016) document that, on average, Chilean college applicants substantially over-estimated the earnings of college graduates, while Delavande and Zafar (2019) document a similar pattern among Pakistani post-secondary students. In the BPS, the evolution of expectations suggests that initial optimism fades as students progress through college, systematically revising their beliefs about postcollege earnings downward. By the end of college, the sample average of $Q_{G+1}^{2}$ falls to roughly $\$ 27,000$, much closer to, though still higher than, average actual post-college earnings.
} 
Figure 1: Joint Distribution of $\rho$ and $\beta$

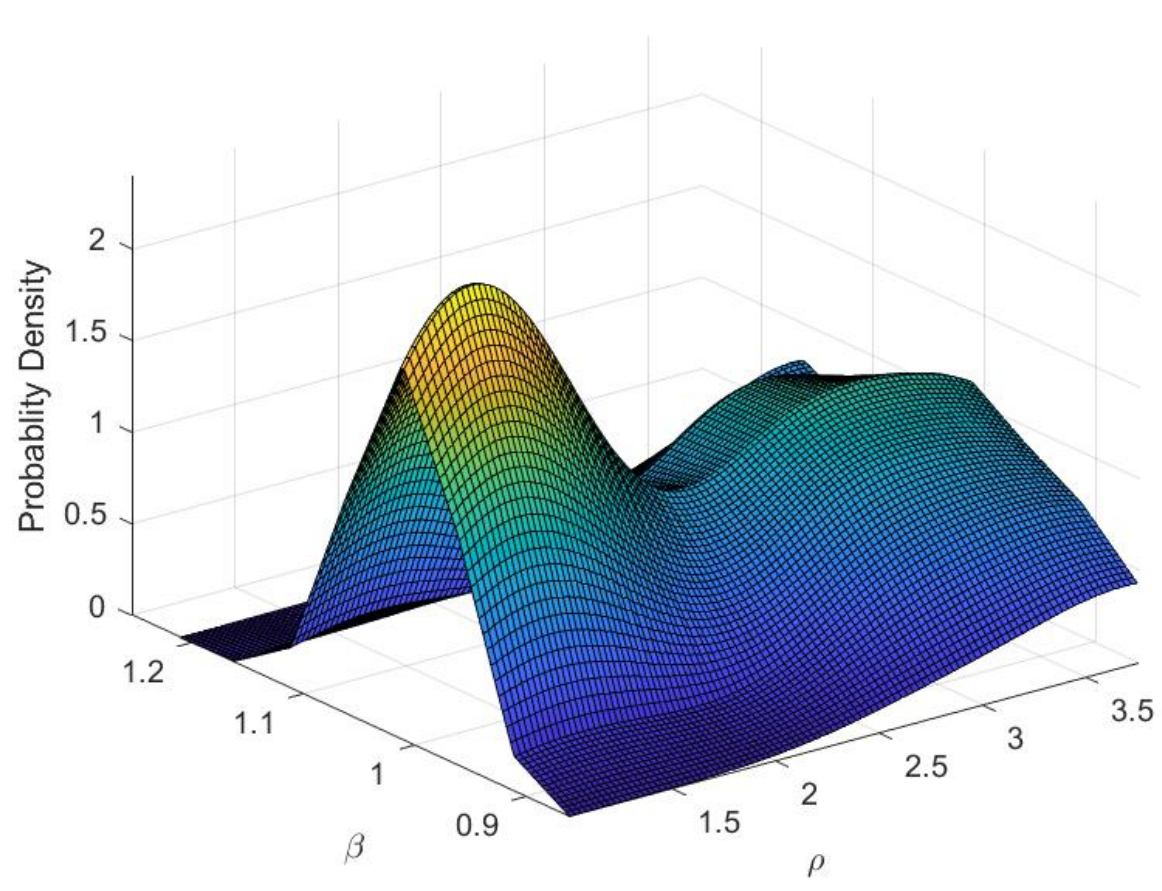

Notes: Distribution is estimated using a Normal kernel function and optimal bandwidth.

Figure 1 depicts the (smoothed) joint distribution for $\rho$ and $\beta$. The sample average of $\rho$ is 2.54 , and there is considerable variation in $\rho$ with an interquartile range of 1.5 to 3.76. The average value of $\beta$ is 1.02 (interquartile range of 0.98 to 1.06), suggesting that the average student in our sample would prefer positive consumption growth even in an environment with a zero interest rate. $^{28}$ Our main analysis uses these elicited values in calculating $\mathcal{V}$. Since the scenarios underlying these preference-eliciting questions were explicitly designed to mimic the type of lifecycle consumption/savings problem we consider, the implied $\beta$ and $\rho$ values are well-suited for our use. We show below that estimated $\mathcal{V}$ are even larger for other commonly assumed parameter values $(\beta=0.95, \rho=2)$.

\footnotetext{
${ }^{28}$ For the $15 \%$ of students who did not answer questions related to $\rho$ and/or $\beta$, we impute this missing information using the respective sample averages.
} 


\section{A Data-Driven Approach}

In this section, we use a data-driven approach to estimate the post-college consumption function needed for calculating individual-specific college consumption values, $\mathcal{V}$, using equation (5). As noted earlier, this approach relies on the assumption that all students have the same post-college consumption function $\tilde{C}\left(D_{G+1}, W_{G+1}\right)$.

\subsection{Estimating the Post-College Consumption Function}

In principle, one could non-parametrically estimate $\tilde{C}\left(D_{G+1}, W_{G+1}\right)$ with cross-sectional data on $C_{G+1}, D_{G+1}$, and $W_{G+1}$. Due to our relatively small sample size, we estimate a second order polynomial in $D_{G+1}$ and $W_{G+1}$ under the constraints that $C_{G+1}$ is decreasing in $D_{G+1}$ within the empirical support of $D_{G+1}$ and increasing in $W_{G+1}$ over the positive real line. This estimation is based on our main post-college sample of 151 single, childless graduates. Further details and coefficient estimates are reported in Appendix I, while the light gray surface in Figure 2 shows the estimated post-college consumption function over the relevant range of debt and earnings. On average, post-college consumption increases by $\$ 0.31$ for every additional $\$ 1$ in earnings and decreases by $\$ 0.08$ for every additional dollar of debt.

Figure 2: Post-college Consumption Function $\tilde{C}\left(D_{G+1}, W_{G+1}\right)$

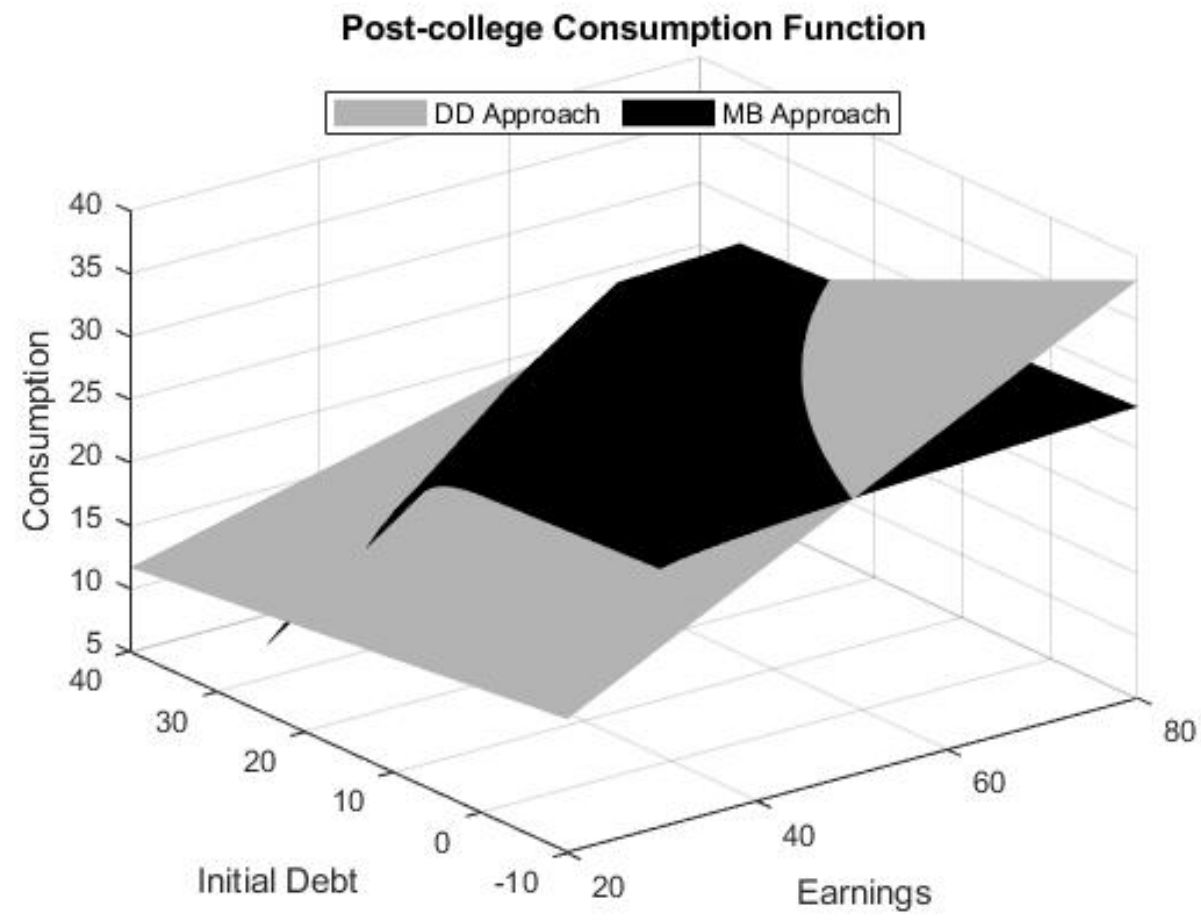




\subsection{The Consumption Value of College}

The assumption that all students have the same consumption function is consistent with homogeneity in preferences and beliefs about lifecycle earnings, interest rates, and borrowing opportunities conditional on student debt and earnings during the first year after college. Hence, we set $\beta$ and $\rho$ to their respective sample averages in applying equation (5) to obtain student-specific consumption values for all 177 students in our main in-school sample. Given this approach, individual heterogeneity in $\mathcal{V}$ comes only from differences in freshmanyear beliefs $F_{1}^{W_{G+1}}$, preferred consumption in college $C_{1}^{e x}+\hat{\delta}$, and preferred student debt $D_{G+1}+(1+r)^{G} \hat{\delta}$.

Given the estimated post-college consumption function, $\tilde{C}(\cdot, \cdot)$, we calculate the expected marginal utility of post-college consumption for each student based on the student's own preferred post-college debt and distribution describing beliefs about post-college earnings

(integrating over $\left.F_{1}^{W_{G+1}}\right)$. Having obtained $E_{1}\left[U^{\prime}\left(C_{G+1}\right)\right]$ for each student, we then use equation (5) to obtain student-specific consumption values, $\mathcal{V}$.

As reported in Table 3, the average consumption value across the students in our sample is $\$ 11,680$, while the median is only slightly lower. Dispersion of $\mathcal{V}$ is moderate with a consumption value of $\$ 7,980$ at the 25 th percentile and $\$ 14,050$ at the 75 th percentile. Despite very low out-of-pocket expenditures, these results indicate that most students at Berea enjoy substantial consumption benefits while enrolled in school. This is generally confirmed by responses to an independent BPS survey question administered during the first year of college, which reveals that $80 \%$ of all students think that being in school is more enjoyable than being out of school.

\subsection{Robustness}

Our DD Approach relies on student responses to several novel survey questions used to determine the preferences, beliefs, and other important features of the Euler equation that are necessary to identify $\mathcal{V}$. In this subsection, we explore the robustness of our results to different assumptions about preferences and to alternative methods for characterizing both the post-college consumption function and subjective beliefs about post-college earnings. Appendix $\mathrm{H}$ reports several additional robustness checks, showing for example, that the estimated distribution of $\mathcal{V}$ is nearly identical to the baseline case in Table 3 when considering the full sample of Berea freshman (including those that are considered debt-averse) or when 
Table 3: Distribution for $\mathcal{V}$ (in $\$ 1,000 \mathrm{~s}$ ) under Alternative Assumptions (DD Approach)

\begin{tabular}{lcccc}
\hline & Mean & 25th Perc. & Median & 75th Perc. \\
\hline Baseline & 11.68 & 7.98 & 11.17 & 14.05
\end{tabular}

A) Alternative Values for $\rho, \beta$, and $r$

\begin{tabular}{|c|c|c|c|}
\hline$\beta=0.95$ and $\rho=2$ & 14.40 & 10.02 & 13.60 \\
\hline$\rho=5$ for the $(3.76, \infty)$ Group & 11.88 & 8.19 & 11.20 \\
\hline$r=8 \%$ & 10.85 & 7.29 & 10.32 \\
\hline
\end{tabular}

B) Alternative Post-College Consumption Function Estimates

$\begin{array}{lcccc}\text { Conservative Extrapolation Assumption } & 9.89 & 7.89 & 10.33 & 12.44 \\ \text { Including Married Individuals } & 10.12 & 6.82 & 9.57 & 12.23 \\ \text { Without Min. Consumption Adjustment } & 10.83 & 6.39 & 9.87 & 13.42 \\ \text { Conservative Measure of Durable Goods } & 10.20 & 6.71 & 9.58 & 12.29\end{array}$

C) Alternative Interpretation of Reported Subjective Earnings Distributions

$\begin{array}{lllll}\text { Unemployed All Year with Probability } P_{G+1}^{U} & 9.27 & 6.09 & 8.97 & 11.49\end{array}$

Notes: Results based on main in-school sample with 177 observations.

employing different approaches to address missing student debt observations; results are also very similar when using data on in-school consumption, desired borrowing, and beliefs measured during the second year of college rather than the first.

\subsubsection{Alternative Assumptions about Preferences and Interest Rates}

Notice that our estimated consumption function, $\tilde{C}(\cdot, \cdot)$, depends only on measures of postcollege consumption, debt, and earnings. It does not depend on preference parameters $(\beta, \rho)$ nor the interest rate $r$. It is then immediately clear from equation (5) that estimated $\mathcal{V}$ are decreasing in both the time discount rate $\beta$ and interest rate $r$ (effects of $\rho$ are generally ambiguous). Intuitively, the more students discount the future, the higher should be desired in-school consumption relative to post-school consumption. Thus, for any observed consumption expenditure amounts and beliefs about post-school earnings, a higher consumption value of college is needed to equate marginal expected utility over time.

Our estimates of $\beta$ are notably higher than values typically assumed in the consumption literature (see Section 3.5). Indeed, the average $\beta$ in our sample exceeds 1 , which implies that the average student prefers positive consumption growth over the lifecycle. Given the inherent challenges in eliciting time and risk preferences for individuals, we also calculate $\mathcal{V}$ using "standard" assumptions for these parameters, setting $\beta=0.95$ and $\rho=2$ for all 
students (Browning, Hansen, and Heckman, 1999). Given the lower value of $\beta$ (and likely more muted effects of the modest change in $\rho$ from 2.5 to 2), it is not surprising that these assumed values yield estimates of $\mathcal{V}$ that are about $\$ 2,000-3,000$ higher than our baseline estimates (see Panel A of Table 3).

We also examine the sensitivity of our results to the baseline assumption that $\rho=3.76$ for those students whose self-reported risk preference places their value of $\rho$ in the range of $(3.76, \infty)$, instead assuming a value of $\rho=5$ for these students. As reported in Panel A of Table 3, the resulting distribution for $\mathcal{V}$ is nearly identical to that of our baseline case.

Our baseline analysis assigns $r=5 \%$. Recognizing that college students may believe borrowing is more costly, we next consider imposing a fairly high interest rate of $r=8 \%$. As shown in the final row of Panel A of Table 3, this only reduces the sample average for $\mathcal{V}$ by about $\$ 800$ relative to the baseline case.

Altogether, these results suggest that reasonable alternative assumptions about preferences and interest rates all yield an average consumption value of college that ranges between $\$ 10,900$ and $\$ 14,400$.

\subsubsection{Alternative Estimates of the Post-College Consumption Function}

In Panel B of Table 3, we consider several alternative robustness checks related to estimation of the post-college consumption function, a key ingredient for our DD Approach. ${ }^{29}$

One practical concern in estimating $\tilde{C}\left(D_{G+1}, W_{G+1}\right)$ is that students' expectations about post-college earnings often exceed their actual post-college earnings. The empirical support of post-college earnings does not cover roughly $30 \%$ of the upper end of the support for students' subjective earnings distributions, requiring extrapolation of the post-college consumption function at these earnings realizations. To examine the sensitivity of our results to this extrapolation, we calculate $\mathcal{V}$ assuming that consumption remains constant above the highest observed post-college earnings level in our sample, i.e., $\tilde{C}(D, W)=\tilde{C}\left(D, \max \left\{W_{G+1}\right\}\right)$ for all $W \geq \max \left\{W_{G+1}\right\}$. This assumption yields lower bound estimates of $\mathcal{V}$ if $\tilde{C}\left(D_{G+1}, W_{G+1}\right)$ is non-decreasing in $W_{G+1}$. As shown in the first row of Panel $\mathrm{B}$ in Table 3, the average consumption value computed under this assumption is $\$ 9,890$ (roughly $15 \%$ lower than the baseline average).

A second challenge in estimation of the post-college consumption function arises because

\footnotetext{
${ }^{29}$ See Appendix Table 13 for estimated consumption function $\tilde{C}(\cdot, \cdot)$ coefficients, average derivatives, and sample sizes for all specifications.
} 
some students are married at $t=G+1$ while our Euler equation characterizes the trade-off faced by single individuals. Our baseline approach addresses this by limiting the analysis to unmarried students. Here, we instead include married graduates in the estimation of $\tilde{C}(\cdot, \cdot)$, assuming that their individual earnings and consumption are one-half their family earnings and consumption, respectively. This shifts the estimated distribution for $\mathcal{V}$ down, reducing the average consumption value of college by less than $10 \%$ (see Panel B in Table 3 ).

Next, we note that our baseline estimates use data from the CES to impute food and housing consumption for graduates living with their parents who report low expenditures on these items. For these individuals, post-college consumption expenditures (especially on food and housing) are likely to understate $C_{G+1}$ due to in-kind parental transfers. Here, we explore the implications of this adjustment by re-estimating the post-college consumption function using all reported consumption amounts, ignoring any potential unpaid benefits associated with living with parents. As shown in Panel B of Table 3, this reduces the average consumption value of college by only about $\$ 800$.

Another concern is that our measure of $C_{G+1}$ may contain expenditures on durable goods such as cars, which could potentially lead to artificially high levels of measured consumption after school. Put another way, the price paid for durable goods may cover utility flows for multiple years. This would also mean that, within a particular consumption category that contains durable goods, such expenditures should tend not to appear repeatedly over a short time horizon. For example, a student who buys a car (or expensive television) at $t=G+1$ is likely to benefit from that car (or television) for several years and is, therefore, unlikely to buy another car (or television) over the next few years. This suggests that the lesser of a student's reported expenditures on a particular category of goods containing durables in $t=G+1$ and the student's reported expenditures on that category in $t=G+2$ should represent a conservative measure of non-durable expenditures for that category in $t=G+1$. We, therefore, take advantage of measured consumption expenditures for 10 categories of goods and services. Among these categories, two plausibly include spending on durable goods: "Car and other travel expenses including gas, car payments, and car insurance" and "Music, computer equipment, TV and stereo equipment, and other electronic equipment". Based on this, we construct an alternative measure of $C_{G+1}$ where, separately for each of these two categories, students' reported consumption expenditures at time $t=G+1$ for the category are replaced by the lesser of the amount reported in $t=G+1$ and $t=G+2$. The 
sample average of this alternative measure is roughly $\$ 710$ lower than the sample average of our baseline measure. We then estimate $\tilde{C}(\cdot, \cdot)$ using these conservative measures of $C_{G+1}$. As shown in the last row of Panel B in Table 3, this alternative yields an average value of $\mathcal{V}$ that is about $\$ 1,500$ less than our baseline average.

\subsubsection{Alternative Interpretation of Reported Subjective Earnings Distributions}

A key feature of the BPS is the elicitation of distributions describing beliefs about future earnings. Due to diminishing marginal utility, consumption decisions tend to be sensitive to the left tail of subjective (future) earnings distributions, since individuals want to avoid even the smallest possibility of near-zero consumption. This makes it particularly important to elicit beliefs about worst-case scenarios for future earnings. Fortunately, as discussed in Section 3.3, the preamble to belief-elicitation questions instructed survey respondents to consider the most salient reason that low earnings could arise - that they might not be working at all in the future.

Nonetheless, to explore whether a sizable consumption value exists even under an especially conservative assumption, we re-estimate consumption values assuming that reported student beliefs reflect the distribution conditional on working (i.e., despite the instructions, students ignore the possibility of not working). For clarity of exposition, we denote reported (conditional) beliefs about earnings in year $t$ as $\underline{F}_{1}^{W_{t}}$, which may now differ from their unconditional subjective beliefs $F_{1}^{W_{t}}$. (We note that this distinction was not needed earlier in our baseline analysis, which assumes that students follow the survey instructions and report unconditional distributions.)

This robustness check takes advantage of a first-year BPS survey question that elicits each student's perceived probability of not working in different post-college years $t, P_{t}^{U}$. These perceived probabilities are quite low for Berea students. On average, $P_{t}^{U}$ is 0.09 in the first post-college year $(t=G+1)$, dropping to about 0.06 both five $(t=G+6)$ and fifteen $(t=G+16)$ years later.

We assume that $P_{t}^{U}$ represents the probability that a student is unemployed for the entire year $t .^{30}$ Generalizing the post-college consumption function to depend on employment status $I_{G+1}$ (an indicator equal to one if the individual is employed and zero otherwise),

\footnotetext{
${ }^{30}$ Appendix H.3 instead considers the case in which $P_{t}^{U}$ reflects the fraction of year $t$ that a student expects to be non-employed. This (likely more realistic) assumption yields an average $\mathcal{V}$ that is only about $\$ 1,000$ less than the baseline estimate.
} 
$\tilde{C}\left(D_{G+1}, W_{G+1}, I_{G+1}\right)$, we modify equation (5) to explicitly account for the two employment possibilities:

$$
\mathcal{V}=\left([\beta(1+r)]^{G} E_{1}\left[\tilde{\tilde{C}}\left(D_{G+1}+(1+r)^{G} \hat{\delta}, W_{G+1}, I_{G+1}\right)^{-\rho}\right]\right)^{-1 / \rho}-C_{1}^{e x}-\hat{\delta},
$$

where the expectation is now taken over beliefs about both employment and earnings conditional on employment. Because earnings are always zero in the unemployed state, we can expand the expression for the expected marginal utility of post-college consumption as follows:

$$
\begin{aligned}
& E_{1}\left[\tilde{\tilde{C}}\left(D_{G+1}+(1+r)^{G} \hat{\delta}, W_{G+1}, I_{G+1}\right)^{-\rho}\right] \\
& =\left(1-P_{G+1}^{U}\right) \int \tilde{\tilde{C}}\left(D_{G+1}+(1+r)^{G} \hat{\delta}, w, 1\right)^{-\rho} d \underline{F}_{1}^{W_{t}}(w)+P_{G+1}^{U} \tilde{\tilde{C}}\left(D_{G+1}+(1+r)^{G} \hat{\delta}, 0,0\right)^{-\rho} .
\end{aligned}
$$

Since our estimated baseline consumption function is based on individuals with positive earnings, $\tilde{\widetilde{C}}\left(D_{G+1}, W_{G+1}, 1\right)$ directly corresponds to the post-college consumption function $\tilde{C}\left(D_{G+1}, W_{G+1}\right)$ estimated in Section 4.1. We assume $\tilde{C}\left(D_{G+1}, 0,0\right)=e^{\alpha_{0}+\alpha_{1} D_{G+1}}$ (ensuring that consumption is strictly positive) and estimate $\left(\alpha_{0}, \alpha_{1}\right)$ via nonlinear least squares using the 24 students who reported that they were unemployed in $t=G+1$. The estimates indicate that post-college consumption is decreasing in accumulated debt and that the implied postcollege consumption for an unemployed graduate with $\$ 5,830$ in debt (the sample average) is roughly equal to that of a working graduate with the same debt who earns $\$ 7,520 .{ }^{31}$

Combining the estimated consumption functions $\tilde{C}\left(D_{G+1}, W_{G+1}, 1\right)$ and $\tilde{C}\left(D_{G+1}, 0,0\right)$, the perceived unemployment probability $P_{G+1}^{U}$, and subjective beliefs about earnings conditional on working, we quantify the college consumption value $\mathcal{V}$ using equations (7) and (8). The results are reported in Panel $\mathrm{C}$ in Table 3, suggesting an average consumption value of $\$ 9,300$, about $20 \%$ lower than the baseline average. This indicates a substantial consumption value of college even under extremely conservative assumptions about how students (mis-)reported their beliefs about future earnings.

\section{Model-Based Approach}

Our Model-Based (MB) Approach assumes that each student's post-college consumption function is determined as the solution to a standard lifecycle consumption allocation problem (with uncertainty and borrowing constraints) from period $t=G+1$ to retirement.

\footnotetext{
${ }^{31}$ Estimated $\alpha_{0}$ is 2.70 (t-statistic of 20.01 ) and $\alpha_{1}$ is -0.06 (t-statistic of 1.91 ).
} 


\subsection{Lifecycle Framework for Post-College Consumption}

In solving the lifecycle problem and mapping ages to $t$, we assume that individuals enter college at age 18 (so $t=1$ at age 18) and work until they retire in year $T=47$ (i.e., age 65). ${ }^{32}$ Taking initial post-college debt and earnings $\left(D_{G+1}, W_{G+1}\right)$ as given and assuming that all debts must be repaid eventually $\left(\bar{D}_{T+1}=0\right)$, individuals

$$
\begin{aligned}
\max _{C_{G+1}, \ldots, C_{T}} E\left[\sum_{t=G+1}^{T} \beta^{t-G-1} U\left(C_{t}\right) \mid D_{G+1}, W_{G+1}\right] \quad \text { subject to } \\
D_{t+1}=\left(D_{t}+C_{t}-\psi\left(W_{t}\right)\right)(1+r) \leq \bar{D}_{t+1} \quad \text { for } t=G+1, \ldots, T,
\end{aligned}
$$

where $\psi(\cdot)$ represents after-tax earnings based on federal and Kentucky tax code in 2001 (see Appendix B). Of interest in our analysis is the optimal consumption function in the first year after college, $\tilde{C}\left(D_{G+1}, W_{G+1}\right)$, which is then used in equation (5) - along with in-school consumption $C_{1}^{e x}$, desired borrowing $\hat{\delta}$, preferences $(\beta, \rho)$, and beliefs $F_{1}^{W_{G+1}}$ - to determine $\mathcal{V}$ for each student.

Two key challenges arise here. First, one must specify post-college borrowing limits in a practical way. To that end, we assume that students can roll over their initial post-college debt and take on at most $\bar{D}$ amount of additional debt after college:

$$
\bar{D}_{t+1}=(1+r)^{t-(G+1)} \max \left\{0, D_{G+1}\right\}+\bar{D} \text {, for } t<T \text { and } \bar{D}_{T+1}=0 .
$$

Because roughly $80 \%$ of the accumulated debt of our Berea graduates comes from student loan programs or parents, this specification is roughly consistent with $\bar{D}$ representing debt limits set by private lenders as in, e.g., Johnson (2013) and Abbott, et al. (2019). This specification guarantees that, for any $\bar{D}>0$, students can afford positive consumption in all periods regardless of earnings realizations. Section 5.2 describes our primary approach to parameterizing $\bar{D}$, while Section 5.4 examines the robustness of our main results (presented in Section 5.3) to alternative specifications for the sequence of debt limits $\left\{\bar{D}_{t+1}\right\}_{t=G+1}^{T}$.

Second, the post-college consumption function depends on both the borrowing limit $\bar{D}$ and beliefs about the lifecycle earnings process. In determining $\mathcal{V}$ in equation (5), beliefs are based on information available as of the first year of college, so the relevant post-college consumption function for that equation depends on both $\bar{D}$ and $\left\{F_{1}^{W_{t}}\right\}_{t=G+2}^{T}$. We can make this dependence explicit by writing the consumption function as $\tilde{C}\left(D_{G+1}, W_{G+1} ; \bar{D},\left\{F_{1}^{W_{t}}\right\}_{t=G+2}^{T}\right)$.

\footnotetext{
${ }^{32}$ In practice, very few students were over age 19 when they entered Berea. We implicitly assume that all students will work 47 years after graduating regardless of when they entered college.
} 


\subsection{Parameterizing the Lifecycle Problem}

In solving the lifecycle problem defined in equation (9), we assume individual-specific preferences $(\beta, \rho)$ as estimated in Section 3.5. We also continue to assume that subjective earnings distributions are described by a shifted log-normal distribution with dynamics determined by an autoregressive process. Beliefs for college freshman are characterized as follows: $\log \left(W_{t}-\underline{W}_{1, t}\right)=\mu_{1, t}+\sigma_{1, t} \epsilon_{t}$, where $\epsilon_{G+1} \sim N(0,1), \epsilon_{t}=\Gamma \epsilon_{t-1}+\eta_{t}$ for $t=G+2, \ldots, T$, and $\eta_{t} \sim N\left(0,1-\Gamma^{2}\right)$ for all $t$.

Since the BPS did not elicit beliefs about earnings autocorrelations, we assume that subjective beliefs about $\Gamma$ match the estimated autocorrelation in realized earnings for the post-college period. Using the autocovariance structure for annual earnings from the unbalanced panel of 10 post-graduation years in the BPS, we estimate $\Gamma=0.62$ via Minimum Distance estimation. ${ }^{33}$ The remaining parameters of the belief distribution for college fresh$\operatorname{man}\left\{\underline{W}_{1, t}, \mu_{1, t}, \sigma_{1, t}\right\}_{t=G+1}^{T}$ are obtained from elicited beliefs about post-college earnings for years $G+1, G+6$, and $G+16$ (i.e., ages 23, 28, and 38), as described earlier in Section 3.3. We follow Stinebrickner and Stinebrickner (2014) in assuming that $\underline{W}_{1, t}, \mu_{1, t}$, and $\sigma_{1, t}$ grow linearly between the observed ages and remain constant after age 38 until retirement.

Finally, we must determine the additional debt limit $\bar{D}$, which we assume is known to all students. Conditional on debt $D_{G+1}$ and earnings $W_{G+1}$, post-college consumption $C_{G+1}$ is increasing in $\bar{D}$ for two reasons: (i) a higher debt limit enables more borrowing and consumption immediately after school, and (ii) a higher debt limit also reduces precautionary savings incentives. Based on this insight, we estimate the value of $\bar{D}$ by equating the sample average of model-implied post-college consumption with the sample average of observed postcollege consumption, $C_{G+1}$, using our main post-college sample of 151 students. ${ }^{34}$ This yields a post-college additional debt limit, $\bar{D}$, of $\$ 11,070$.

\footnotetext{
${ }^{33}$ Studies from the earnings dynamics literature sometimes estimate much higher values of $\Gamma$ (see Meghir and Pistaferri (2011) for a review). We, therefore, consider a value of $\Gamma=0.9$ in Appendix H.4. This yields a slightly lower average $\mathcal{V}$ than our baseline case.

${ }^{34}$ We note that solving for $\bar{D}$ is complicated by the fact that beliefs about earnings in years $t=G+2, \ldots, T$ may change between college entry and the first year after college (i.e., $F_{1}^{W_{t}}$ need not equal $F_{G+1}^{W_{t}}$ for $t=$ $G+2, \ldots, T)$. As discussed in Appendix D, we use beliefs elicited in period $G+1$ to determine modelbased consumption levels in period $G+1$ (from the problem in equation (9)) to compare with actual post-college consumption, $C_{G+1}$, in estimating $\bar{D}$. Once $\bar{D}$ has been estimated, we re-solve the problem in equation (9) using beliefs elicited during the first year of college to obtain the consumption function $\tilde{C}\left(D_{G+1}, W_{G+1} ; \bar{D},\left\{F_{1}^{W_{t}}\right\}_{t=G+2}^{T}\right)$ used in estimating $\mathcal{V}$.
} 


\section{$5.3 \quad$ Results}

Having parameterized the model, for each student, we numerically solve for the post-college consumption function and calculate $\mathcal{V}$. Figure 2 shows the implied consumption function

(in black), $\tilde{C}\left(D_{G+1}, W_{G+1}\right)$, for a representative student (i.e., preference and post-college belief distribution parameters are set to their sample averages). Comparing this with the consumption function estimated using the DD Approach, we see a much sharper reduction in consumption for very high debt and low earnings levels; otherwise, the model-implied postcollege consumption function is relatively flat in debt and earnings. The two consumption functions imply consumption levels that are slightly higher in the MB case, except when earnings are very low and debt very high or when the reverse is true.

As reported in Table 4, the average consumption value from the MB Approach, $\$ 15,110$, is almost $\$ 3,500$ higher than the benchmark average from the DD Approach (see Table 3), while the median is quite similar. The MB Approach reveals considerably more dispersion in $\mathcal{V}$ relative to the DD Approach, with a nearly $\$ 20,000$ interquartile range (from $\$ 4,100$ to $\$ 23,960)$. This greater heterogeneity is partly due to the incorporation of heterogeneity in $\rho$ and $\beta$. It is also consistent with the fact that students with low expectations about earnings immediately after school also tend to have low expectations about subsequent earnings. This implies less consumption conditional on post-college debt and earnings due to precautionary motives, which is not captured by a homogeneous consumption function that only depends on $\left(D_{G+1}, W_{G+1}\right)$ as in Section 4 .

\subsection{Robustness}

In this subsection, we examine the robustness of our MB results to a few alternative assumptions. Most notably, we consider the case where students mistakenly report beliefs about post-college earnings conditional on employment (rather than unconditionally as instructed), and we explore alternative assumptions about post-college lifecycle borrowing constraints. Appendix $\mathrm{H}$ considers several additional robustness checks. ${ }^{35}$

\footnotetext{
${ }^{35}$ For example, Appendix $\mathrm{H}$ shows that the estimated distribution of $\mathcal{V}$ is nearly identical to the baseline case in Table 3 when considering the full sample of Berea freshman (including those that are considered debt-averse) or when we take a different approach to imputing missing post-college debt observations. Consumption values are also very similar when using sophomore- rather than freshman-year data from college.
} 
Table 4: Distribution for $\mathcal{V}$ (in $\$ 1,000$ s) under Alternative Assumptions (MB Approach)

\begin{tabular}{lcccc}
\hline & Mean & 25th Perc. & Median & 75th Perc. \\
\hline Baseline & 15.11 & 4.10 & 11.10 & 23.96
\end{tabular}

A) Alternative Values for $\rho, \beta$, and $r$

\begin{tabular}{|c|c|c|c|}
\hline$\beta=0.95$ and $\rho=2$ & 27.02 & 19.06 & 25.86 \\
\hline$\rho=5$ for the $(3.76, \infty)$ Group & 15.81 & 4.25 & 11.97 \\
\hline$r=8 \%$ & 12.38 & 2.11 & 9.04 \\
\hline
\end{tabular}

B) Alternative Interpretation of Reported Subjective Earnings Distributions

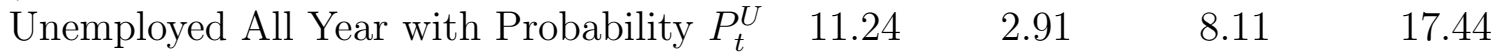

C) Alternative Post-College Consumption Function Estimates

\begin{tabular}{lcccc} 
Conservative Borrowing Limit & 10.00 & 0.94 & 7.30 & 17.56 \\
Aiyagari Borrowing Limit & 19.02 & 4.21 & 12.07 & 26.58 \\
\hline
\end{tabular}

Notes: Results based on main in-school sample with 177 observations.

\subsubsection{Alternative Assumptions about Preferences and Interest Rates}

Panel A of Table 4 reports the distributions of $\mathcal{V}$ under alternative assumptions about preferences and interest rates. While our results are insensitive to a higher assumed value for $\rho$ when self-reports place it in the highest range, we obtain substantially higher college consumption values when assuming conventional values for discount rates and risk aversion $(\beta=0.95$ and $\rho=2)$. Consumption values of college are about $\$ 2,000-3,000$ lower than our baseline MB estimates if we assume a higher interest rate of $8 \%$ (rather than 5\%).

Given the economics of the problem, it is not surprising that the direction of these changes in $\mathcal{V}$ distributions are the same as observed for the DD cases. However, the changes are more dramatic here. This is likely due to the fact that individual-specific post-college consumption functions derived as solutions to the lifecycle consumption problem (in the MB Approach) change with adjustments in preferences or interest rates, whereas the DD approach takes the consumption function directly from the data and is invariant to assumptions about $(\beta, \rho)$ and $r$. More importantly, all of these alternative assumptions imply an average consumption value of college that exceeds $\$ 12,000$.

\subsubsection{Alternative Interpretation of Reported Subjective Earnings Distributions}

As with the DD Approach, we consider the robustness of our MB estimates of $\mathcal{V}$ to the conservative assumption that reported subjective belief distributions refer to beliefs conditional 
on working rather than the unconditional distribution that was explicitly requested. As in Section 4.3.3, we let $F_{1}^{W_{t}}$ reflect the true unconditional distribution of beliefs and $\underline{F}_{1}^{W_{t}}$ reflect the reported beliefs, assumed here to be conditional on working.

We again take advantage of students' perceived probabilities of not working in future years, $P_{t}^{U}$, to determine beliefs about the unconditional distribution of future earnings, $F_{1}^{W_{t}}$, in order to estimate $\mathcal{V}$. Because we must solve the full lifecycle consumption/savings problem, we use elicited beliefs about $P_{t}^{U}$ for years $t=G+1, t=G+6$, and $t=G+16$, interpolating in a linear manner between those years and assuming $P_{t}^{U}$ remains constant after $t=G+16$.

Here, we continue to obtain the post-college consumption functions for those who are working after school, $\tilde{C}\left(D_{G+1}, W_{G+1}, 1\right)$, and for those who are not working after school, $\tilde{C}\left(D_{G+1}, 0,0\right)$, as solutions to appropriately modified versions of the maximization problem in equation (9). In each case, students believe that they face a probability $P_{t}^{U}$ of being unemployed in each future year $t$, in which case they receive the maximum allowable 26 weeks of unemployment benefits, $\$ 234 \times 26=\$ 6,084 .{ }^{36}$ Otherwise, with probability $1-P_{t}^{U}$, they will be employed with their beliefs about $W_{t}$ described by $\underline{F}_{t}^{W}$ taken from their elicited reports. All other elements of our model remain unchanged.

Combining knowledge of the post-college consumption functions $\tilde{C}\left(D_{G+1}, W_{G+1}, 1\right)$ and $\tilde{\widetilde{C}}\left(D_{G+1}, 0,0\right)$, the unemployment probability $P_{G+1}^{U}$, and the subjective beliefs about postcollege earnings conditional on working $\underline{F}_{t}^{W}$, we quantify the college consumption value $\mathcal{V}$ using equations (7) and (8). Panel B of Table 4 shows the estimated distribution of $\mathcal{V}$, which averages more than $\$ 11,000$. Thus, our MB Approach suggests sizable consumption values of college even under the assumption that, when reporting beliefs about future earnings, respondents deviate from the stated survey instructions in seemingly the most problematic way.

\subsubsection{Alternative Assumptions about Borrowing Limits}

The MB Approach requires a specification for borrowing limits faced by students. Our baseline specification, equation (10), is quite flexible and allows us to parameterize the borrowing limit to match observed post-college consumption levels. Here, we consider two alternative specifications that are less flexible but allow us to examine the robustness of our

\footnotetext{
${ }^{36}$ According to data from the Employment and Training Administration, the average weekly payment for unemployment insurance benefits in Kentucky was $\$ 234$ in 2001 . Unemployed workers can qualify for a maximum of 26 weeks of benefits during each unemployment spell.
} 
consumption value estimates to other reasonable specifications.

We first consider a specification of extremely limited borrowing opportunities, which provides very conservative estimates of $\mathcal{V}$. This specification restricts students from taking on any new debt after college but allows them to roll over some of their student debt after leaving school. In particular, we assume that, for each student and each period $t$, the current value of total previous repayments must be no less than the current value of total (perceived) minimum earnings in all previous periods:

$$
\bar{D}_{t+1}=\max \left\{0,(1+r)^{t-(G+1)} D_{G+1}-\sum_{t^{\prime}=G+1}^{t}(1+r)^{t+1-t^{\prime}} \psi\left(\underline{W}_{t^{\prime}}\right)\right\} .
$$

Only $9 \%$ of students in our sample ever (expect to) face non-zero borrowing limits. This only arises during the first several years after college, and the limits are quite modest. Panel $\mathrm{C}$ in Table 4 shows that, even under this conservative specification, the average college consumption value is still as high as $\$ 10,000$.

Next, we consider the natural borrowing limit of Aiyagari (1994) based on the perceived lower bound on earnings reported by students:

$$
\bar{D}_{t+1}=\sum_{t^{\prime}=t+1}^{T}(1+r)^{t-t^{\prime}} \psi\left(\underline{W_{t^{\prime}}}\right) .
$$

The second row of Panel $\mathrm{C}$ shows that Aiyagari-type borrowing constraints imply a much higher average $\mathcal{V}(\$ 19,020)$ than under the baseline assumptions. Because the lowest perceived post-college earnings level is quite high for Berea freshman, the Aiyagari-type constraint is fairly loose for most students - even the most constrained student expects to be able to borrow more than $\$ 16,000$ during the first year after college. Due to the greater perceived access to credit, youth behave roughly as if they are unconstrained. There is little incentive for precautionary savings, resulting in high levels of consumption immediately after college.

\section{Heterogeneity, Returns to College, and Price Dis- counts}

In this section, we explore several important issues related to the consumption value of college. First, we estimate the extent to which average college consumption values vary across students with different backgrounds. Second, we show that the consumption value of 
college is an important component of the total expected return to college for Berea students. Third, we show that accounting for the consumption value of college dramatically reduces the estimated marginal value of relaxing student borrowing limits relative to an approach that ignores any consumption benefits. Fourth, we consider consumption benefits of college that are only substitutable with non-housing goods and services, estimating the (non-housing) consumption value of college under this assumption. Fifth, we consider the possibility that college students may receive discounted pricing on many goods and services, estimating this price discount as well as a lump-sum consumption value associated with college.

\subsection{Heterogeneity in Consumption Values}

Our two approaches yield considerable cross-sectional heterogeneity in college consumption values, as shown in Figure 3, which plots the estimated distribution functions for $\mathcal{V}$ based on our baseline estimates for both the DD and MB Approaches. This is important, because it suggests that even students who choose to attend the same institution - and therefore, enjoy similar campus and local opportunities - appear to place very different values on those opportunities (or avail themselves of different opportunities).

Figure 3: CDF of the Sample Distribution of $\mathcal{V}$

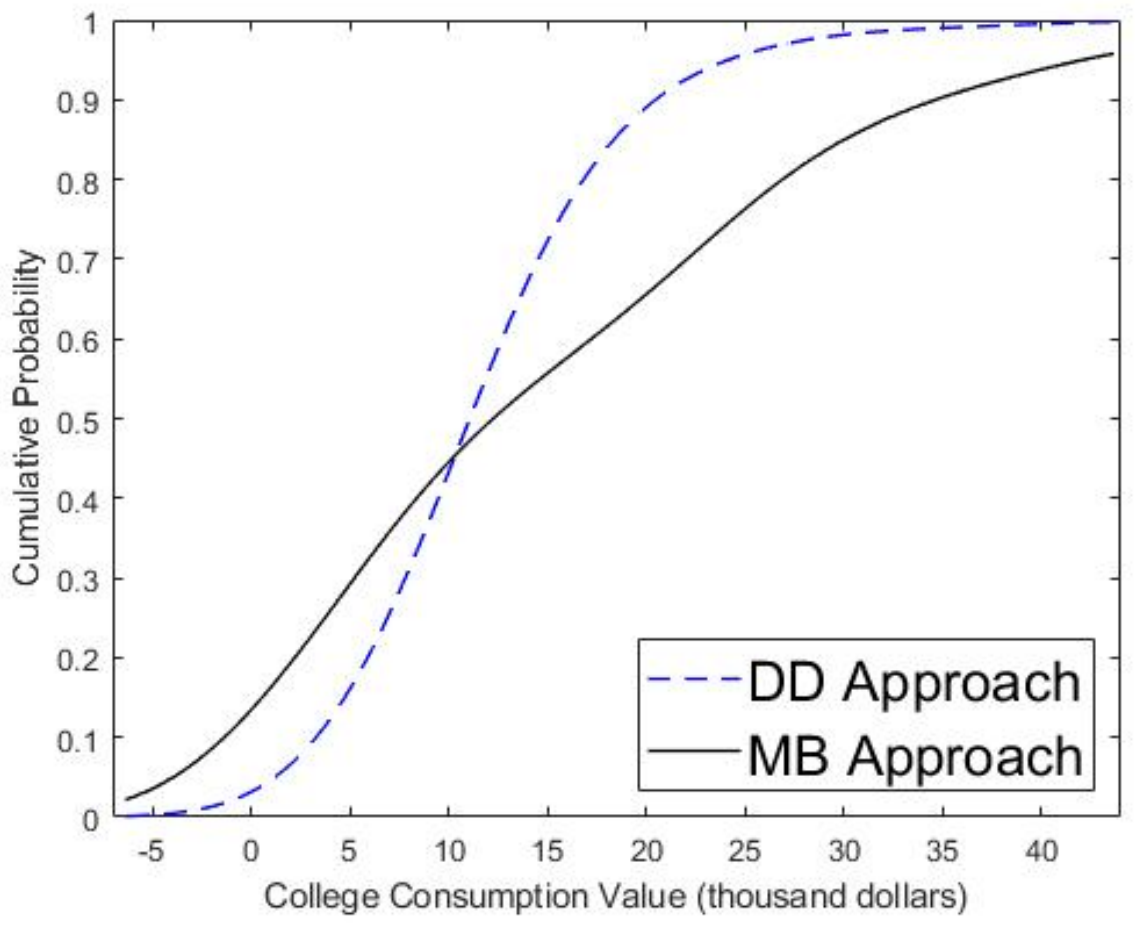


While students at Berea are much more homogeneous than the population of American youth at large (especially in terms of family income), it is still interesting to explore whether differences in their consumption values of college can be explained by such factors as gender, race, final high school grade point average (GPA), and total family income (reported during the first year of college). Table 5 reports the estimated effects of these student characteristics on various measures of consumption (and $\mathcal{V}$ ) using standard linear regressions. ${ }^{37}$ We let $\mathcal{V}^{\mathcal{D D}}$ and $\mathcal{V}^{\mathcal{M B}}$ represent the consumption values computed using the DD and MB Approaches, respectively.

As shown in the first row of Table 5, the only statistically significant predictor of observed in-school expenditures, $C_{1}^{e x}$, is race. Black students spent roughly $\$ 400$ less per year while in college. However, the second row of Table 5 shows that black Berea students did not have statistically lower total desired consumption $\left(C_{1}^{e x}+\hat{\delta}\right)$ than other students, suggesting that black students may be more credit constrained. This is generally consistent with lower wealth among black families, even when conditioning on family income (Barsky et al., 2002; Oliver and Shapiro, 1997).

Turning attention to the consumption value of college, we again estimate statistically significant differences by race. The consumption value of black students is estimated to be $\$ 2,920$ and $\$ 6,790$ higher than the consumption value of non-black students under the DD and MB Approaches, respectively. This difference may help explain why Stinebrickner and Stinebrickner (2014) find that black students are more likely to remain enrolled at Berea conditional on other observed factors (e.g., college grades). There is also some evidence of differences in consumption values by gender. Based on the DD approach, the consumption value is estimated to be $\$ 2,130$ higher for males than for females, which is not too surprising in light of the fact that male students at Berea devote less time to studying than their female counterparts (Stinebrickner and Stinebrickner, 2012). Altogether, the characteristics we consider explain no more than $5 \%$ of the variation in all of the consumption measures reported in Table $5 .{ }^{38}$

\footnotetext{
${ }^{37}$ Similar regressions for time and risk preferences $(\beta$ and $\rho$ ) suggest that little of the variation in these preferences can be explained by the observable factors. This is likely due to the relatively modest heterogeneity in background characteristics among Berea students (see Appendix A.4).

${ }^{38}$ Table 5 shows that family income does not tend to be significantly related to the consumption measures we examine. This is likely due to the fact that: (1) there is little variation in family income for Berea students, and (2) the reported yearly family income variable used in the regressions is a noisy measure of long-term family income. These issues have led most previous research using the BPS to view the sample as fairly homogeneous in terms of (low) family income.
} 
Table 5: Regression Results: Consumption Value (in $\$ 1,000$ s)

\begin{tabular}{ccccccc}
\hline & $C_{1}^{e x}$ & $C_{1}^{e x}+\hat{\delta}$ & $\mathcal{V}^{\mathcal{D D}}$ & $\mathcal{V}^{\mathcal{M B}}$ & $C_{1}^{e x}+\hat{\delta}+\mathcal{V}^{\mathcal{D D}}$ & $C_{1}^{e x}+\hat{\delta}+\mathcal{V}^{\mathcal{M B}}$ \\
\hline \multirow{2}{*}{ Constant } & 7.850 & 9.360 & 4.411 & 7.141 & 13.771 & 16.501 \\
& $(0.529)$ & $(0.617)$ & $(3.588)$ & $(8.590)$ & $(3.525)$ & $(8.621)$ \\
Male & -0.041 & -0.026 & 2.130 & 3.104 & 2.105 & 3.079 \\
& $(0.138)$ & $(0.309)$ & $(0.938)$ & $(2.245)$ & $(0.921)$ & $(2.254)$ \\
Black & -0.437 & -0.137 & 2.919 & 6.788 & 2.782 & 6.651 \\
\multirow{3}{*}{ HS GPA } & $(0.188)$ & $(0.837)$ & $(1.277)$ & $(3.056)$ & $(1.254)$ & $(3.067)$ \\
\multirow{2}{*}{ Family Income } & -0.116 & -0.483 & 1.558 & 1.203 & 1.075 & 0.720 \\
& $(0.143)$ & $(0.048)$ & $(0.972)$ & $(2.328)$ & $(0.955)$ & $(2.336)$ \\
$R^{2}$ & -0.004 & -0.005 & 0.017 & 0.047 & 0.012 & 0.042 \\
& $(0.004)$ & $(0.004)$ & $(0.024)$ & $(0.058)$ & $(0.024)$ & $(0.058)$ \\
\hline
\end{tabular}

Notes: Each column reflects a separate regression with the reported consumption value as the dependent variable. Family income measured in \$1,000s. Standard errors are in parentheses. Sample size is $17 \%$.

\subsection{Consumption Value and the Expected Return to College}

One concrete way to view the quantitative importance of the consumption value $\mathcal{V}$ is to consider its effect on the return to college. To do this, we use students' subjective beliefs about future earnings in both college and non-college scenarios elicited in the baseline BPS survey at the beginning of college. We consider the 170 students (out of 177) from our main in-school sample who have valid responses to these questions.

The average expected lifetime earnings of the college and non-college options (evaluated at age 18) are $\$ 852,000$ and $\$ 544,000$, respectively. Ignoring the college consumption value (as is typical of the literature), these figures imply a monetary return to college of 56.6 percent. Taking into account four years of the average consumption value of college raises the total return to college by $14.1 \%$ (8.0 percentage points) based on the DD Approach and $18.4 \%$ (10.4 percentage points) based on the MB Approach. ${ }^{39}$ We note that these numbers likely understate the full importance of the consumption value, since the marginal utility of consumption during college generally exceeds the discounted expected marginal utility after graduation for constrained students. This understatement is likely to be quite modest, however, given that only $30 \%$ of Berea students wanted to borrow more and the amounts they wanted to borrower were small.

\footnotetext{
${ }^{39}$ These calculations are based on our baseline DD and MB estimates of $\mathcal{V}$, assuming a $5 \%$ interest rate in discounting lifetime earnings through age 65 and the consumption value flows from college.
} 


\subsection{Value of Relaxing the College Borrowing Constraint}

Borrowing constraints limit the ability of individuals to smooth consumption over time, reducing the value of attending college. While most of the literature focuses on the impacts of credit market distortions on college-going decisions (Lochner and Monge-Naranjo, 2012), the inability to smooth consumption can also reduce the lifetime utility of students who choose to attend college.

To better understand the costs of borrowing limits, notice that the post-college consumption/savings problem in equation (9) can be extended back to the schooling period with an additional constraint on the total debt that can be accumulated through the end of college, $\bar{D}_{G+1}$. Letting $\lambda_{G+1}$ reflect the Lagrange multiplier on this cumulative college debt constraint, the Euler equation relating consumption during the first year of college and first year after finishing can be written as

$$
U^{\prime}\left(C_{1}\right)=[\beta(1+r)]^{G} E_{1}\left[U^{\prime}\left(C_{G+1}\right)\right]+(1+r)^{G} \lambda_{G+1},
$$

where the Envelope Condition tells us that $\lambda_{G+1} \geq 0$ equals the marginal lifetime utility value of increasing the cumulative college borrowing limit $\bar{D}_{G+1}$. Dividing $(1+r)^{G} \lambda_{G+1}=$ $U^{\prime}\left(C_{1}\right)-[\beta(1+r)]{ }^{G} E_{1}\left[U^{\prime}\left(C_{G+1}\right)\right]$ by the marginal utility of consumption, $U^{\prime}\left(C_{1}\right)$, yields a student's willingness-to-pay for the opportunity to borrow one additional dollar (i.e., a $(1+r)^{G}$ dollar increase in $\left.\bar{D}_{G+1}\right)$ as a college freshman, WTP. This WTP is strictly positive (but less than one) for students that are borrowing constrained and zero for those that are unconstrained. See Appendix J for details on equation (11) and WTP.

Because $U^{\prime}\left(C_{1}^{e x}\right)>U^{\prime}\left(C_{1}^{e x}+\mathcal{V}\right.$ ) (assuming $\mathcal{V}>0$ ), ignoring the consumption value of college leads to an overstatement of the willingness-to-pay for additional borrowing. Table 6 shows just how much, reporting this willingness-to-pay based only on observed consumption expenditures (i.e., assuming $\mathcal{V}=0$ ), $W T P^{e x}$, and when incorporating estimated consumption values for each student, $W T P^{\mathcal{V}}$, based on our DD and MB Approaches. Ignoring the consumption value of college, we would conclude that students are, on average, willing to pay considerable amounts to borrow more - as much as 86 cents per additional dollar based on the DD Approach. Perhaps more surprising, we see similarly high $W T P^{e x}$ for students regardless of whether they report that would like to borrow more (i.e., constrained vs. unconstrained).

Accounting for $\mathcal{V}$, students are willing to pay much less to increase their borrowing limit: those who are unconstrained would not be willing to give up any money to borrow more, 
Table 6: Average Willingness-to-Pay for One Additional Dollar of Borrowing

\begin{tabular}{lccc}
\hline & $\begin{array}{c}\text { Ignores } \mathcal{V} \\
\left(W T P^{e x}\right)\end{array}$ & $\begin{array}{c}\text { Accounts for } \mathcal{V} \\
\left(W T P^{\mathcal{V}}\right)\end{array}$ & $W T P^{\mathcal{V}} / W T P^{e x}$ \\
\hline A) DD Approach & & & 0.059 \\
Full Sample (177 respondents) & 0.861 & 0.046 & 0.173 \\
Borrowing Constrained (60 respondents) & 0.857 & 0.135 & 0 \\
Unconstrained (117 respondents) & 0.864 & 0 & \\
& & & 0.033 \\
B) MB Approach & & 0.038 & 0.098 \\
Full Sample (177 respondents) & 0.581 & 0.113 & 0 \\
Borrowing Constrained (60 respondents) & 0.698 & 0 & \\
Unconstrained (117 respondents) & 0.522 & & \\
\hline
\end{tabular}

Notes: Willingness-to-pay reflects the amount of money a college freshman would be willing to pay to be able to borrow an additional dollar. Sample averages are reported (in 2001 dollars) based on the main in-school sample and baseline assumptions.

while those who report that they are constrained would be willing to pay 11-14 cents to borrow an additional dollar. The final column shows that accounting for the consumption value of college reduces the estimated amount constrained students would be willing to pay by 83-90\%. These results highlight the importance of accounting for the consumption benefits of college when considering policies aimed at alleviating borrowing constraints.

\subsection{Non-housing Consumption Value}

In this section, we consider an alternative specification for the contemporaneous utility function where housing consumption $C^{h}$ is not directly/perfectly substitutable with other consumption goods $C^{o}$. Specifically, we assume that the overall contemporaneous utility function $\tilde{U}\left(C^{o}, C^{h}\right)$ is separable in $C^{o}$ and $C^{h}$ :

$$
\tilde{U}\left(C^{o}, C^{h}\right)=U^{o}\left(C^{o}\right)+U^{h}\left(C^{h}\right),
$$

where $U^{o}\left(C^{o}\right)=\frac{\left(C^{o}\right)^{1-\rho}}{1-\rho}$. In the post-college period, $C_{t}^{o}$ and $C_{t}^{h}$ are assumed to equal the expenditures on other consumption goods and housing, respectively. During college, we assume that students receive free consumption benefits from college, so $C_{1}^{o}=C_{1}^{o, e x}+\mathcal{V}^{o}$ and $C_{1}^{h}=C_{1}^{h, e x}+\mathcal{V}^{h}$, where $\mathcal{V}^{o}$ and $\mathcal{V}^{h}$ reflect the consumption benefits of college that are substitutable with non-housing $\left(C_{1}^{o, e x}\right)$ and housing-related $\left(C_{1}^{h, e x}\right)$ purchases, respectively.

In the first year of college, most Berea students lived in the dorm, hence $C_{1}^{h}$ was, to a large extent, exogenously set by the college. This has two important implications. First, 
we cannot apply the Euler equation approach to identify $\mathcal{V}^{h}$, because students were unable to smooth their housing consumption. Second, survey-reported in-college expenditures and the desired additional loan $\hat{\delta}$ all go towards non-housing consumption goods. Hence, we can modify equation (5) as follows to identify the non-housing consumption value, $\mathcal{V}^{o}$ :

$$
\mathcal{V}^{o}=\left([\beta(1+r)]^{G} E\left[\tilde{C}^{o}\left(D_{G+1}+(1+r)^{G} \hat{\delta}, W_{G+1}\right)^{-\rho}\right]\right)^{-1 / \rho}-C_{1}^{o, e x}-\hat{\delta},
$$

where $C_{1}^{o, e x}$ reflects self-reported in-college expenditures (excluding room and board) plus the annual value of food provided as part of Berea's room and board. ${ }^{40}$

We adopt the DD Approach to estimate the non-housing post-college consumption function $\tilde{C}^{o}\left(D_{G+1}, W_{G+1}\right)$ using realized data on $D_{G+1}, W_{G+1}$, and non-housing post-college consumption $C_{G+1}^{o} \cdot{ }^{41}$ The non-housing consumption value $\mathcal{V}^{o}$ is quite substantial with a sample average of $\$ 10,650$, about $\$ 1,000$ smaller than our baseline DD estimate of average overall consumption value $\mathcal{V}$. The interquartile range for $\mathcal{V}^{o}$ goes from $\$ 7,680$ to $\$ 12,470$, while the median value in our sample is $\$ 9,990$.

\subsection{Lump-Sum Consumption Value and Price Discounts}

Our focus on the lump-sum consumption value of college specified in equation (2) is natural since many benefits associated with college (e.g. recreational facilities or friends living in close proximity) are effectively free for students. At the same time, students may receive discounted prices on many other goods and services (e.g. student discounts at nearby establishments).

Assuming any price discounts during college apply to all expenditures besides room and board at Berea, the mapping from consumption expenditures to effective consumption becomes

$$
C_{1}=\frac{C_{1}^{o t h}}{\pi}+C^{f h}+\mathcal{V}
$$

where $\pi>0$ is the price of purchased goods in college (relative to the price of goods purchased after college, normalized to one). Then, the modified Euler equation analogous to

\footnotetext{
${ }^{40}$ Recall that the annual value for food and housing, $C^{f h}$, is $\$ 6,350$. Using reported post-college consumption data (accounting for in-kind transfers for graduates living with their parents), we find that the ratio of average food expenditure to average food and housing expenditures is roughly 0.254. Letting $C^{f}=\$ 6,350 \times 0.254=\$ 1,610$, we define $C_{1}^{o, e x}=C_{1}^{o t h}+C^{f}$, where $C_{1}^{o t h}$ is defined earlier in Section 3.3 as total reported expenditures on all items except Berea-provided room and board (and textbooks).

${ }^{41}$ Conveniently, the DD Approach requires no assumptions on $U^{h}(\cdot)$ or $C_{G+1}^{h}$, while the MB Approach would require a full specification of preferences and observations on post-college housing.
} 
equation (5) is

$$
\underbrace{\left([\beta(1+r)]^{G} E\left[\hat{C}_{G+1}^{-\rho}\right]\right)^{-1 / \rho}}_{\Omega}=\pi^{\frac{1}{\rho}-1}\left(C_{1}^{o t h}+\hat{\delta}\right)+\pi^{\frac{1}{\rho}}\left(C^{f h}+\mathcal{V}\right) .
$$

Note that we have already computed $\Omega$ for each student using the DD (Section 4) and MB (Section 5) Approaches. Assuming $\pi$ and $\mathcal{V}$ are common across students, their values can be estimated by exploiting cross-sectional variation in $\left(C_{1}^{o t h}+\hat{\delta}\right)$ and $\rho$. Specifically, letting $i$ subscripts denote values for student $i$, the following regression can be estimated via non-linear least squares:

$$
\Omega_{i}=\pi^{\frac{1}{\rho_{i}}-1}\left(C_{1, i}^{o t h}+\hat{\delta}_{i}\right)+\pi^{\frac{1}{\rho_{i}}}\left(C^{f h}+\mathcal{V}\right)+\nu_{i}
$$

where $\nu_{i} \Perp\left(C_{1, i}^{\text {oth }}+\hat{\delta}_{i}, \rho_{i}\right)$ reflects measurement error in $\Omega_{i} \cdot{ }^{42}$

Since the DD Approach does not allow for heterogeneity in $\rho$, we estimate equation (12) with $\Omega_{i}$ computed using the MB Approach. We obtain an estimate for $\pi$ of 0.52 , suggesting that Berea students receive a discount of about $50 \%$ on the goods they purchase. The estimated $\mathcal{V}$ is $\$ 22,090$, which is about $\$ 7,000$ higher than the average value obtained from the MB Approach of Section 5 that abstracts from price discounts. The total consumption value of college is given by $C_{1}-C_{1}^{e x}=\frac{1-\pi}{\pi} C_{1}^{o t h}+\mathcal{V}$. Using average $C_{1}^{e x}$ and estimated $(\pi, \mathcal{V})$, students receive an average annual total consumption value from college of $\$ 22,930$. Because spending during college is so low, the price discount channel accounts for less than $5 \%$ of this value.

\section{Conclusions}

The well-known but rarely studied "consumption" benefits of college — from access to sports and recreation facilities to dorm and campus activities to frisbee on the quad - have never been more in the spotlight than during the current pandemic. This paper provides the first available estimates of the total value of all benefits associated with college attendance that are substitutable for other purchased goods and services, i.e., the consumption value of college.

\footnotetext{
${ }^{42}$ For homogeneous $\rho$, a standard linear regression of $\Omega_{i}$ on $\left(C_{1, i}^{\text {oth }}+\hat{\delta}_{i}\right)$ yields estimates of $\pi^{\frac{1}{\rho}-1}$ and $\pi^{\frac{1}{\rho}} \mathcal{V}$ from which estimates of $(\pi, \mathcal{V})$ can be obtained. Unfortunately, we do not have sufficient variation in desired consumption alone to obtain precise estimates in this case.
} 
Unfortunately, these benefits are not easily quantified. For example, it is tempting to think that the consumption value might be estimated from changes in prices charged by post-secondary institutions (and/or in enrollment rates) associated with moves to online instruction during the current pandemic. However, such an approach faces the fundamental challenge that remote learning also likely impacts academic quality and content. The hedonic willingness-to-pay approach taken by Jacob, McCall, and Stange (2018) has provided useful estimates of the marginal valuation of quantifiable amenities, but this general approach also suffers from the challenge of separating consumption from educational benefits for certain amenities. It is equally difficult to measure (or even comprehensively list) all potential benefits accruing to students. More importantly, it is unclear how to go from estimated marginal valuations of college amenities to a measure of the total valuation of consumption benefits associated with college. In light of these challenges, our analysis offers a promising methodological contribution that exploits the well-understood Euler equation to identify the total consumption value of college. While we rely on survey data not typically collected and study a single institution, there is nothing to preclude the handful of survey questions critical for our approach from being added to general longitudinal surveys in the future. Our empirical findings suggest that this would likely be both valuable and could open up several new lines of research.

Specifically, our results indicate that the students we study, on average, receive $\$ 10,000+$ in consumption benefits from each year of college attendance. Factoring in four years of these benefits raises the total anticipated return to college by as much as $18 \%$, on average. We also document considerable heterogeneity in these benefits across students, which suggests that the consumption value of college is likely a major factor in determining who attends college in addition to overall attendance rates. Accounting for these benefits (or at least recognizing their existence) is, therefore, critical for higher education policy. Most notably, many students may not need financial aid to cover much more than their tuition, room, and board costs to attain high levels of effective consumption during college. As such, our results have important implications for empirical studies of credit constraints, since low levels of consumption expenditures during college do not necessarily imply binding constraints. Indeed, we find that accounting for the consumption value of college greatly reduces the estimated marginal value of expanding student borrowing opportunities for those who choose to enroll. 
While caution is appropriate when studying a single school, for reasons described in Section 3.1, it is likely that the college experience at Berea is similar to that at many other institutions, especially smaller liberal arts colleges, which are present throughout the U.S. Of course, the consumption value associated with attendance at large public universities or institutions in major American cities may differ non-trivially. Wealthy students attending elite private institutions may also enjoy different experiences while in college. In terms of future work, it would be informative to determine whether consumption values differ systematically across schools in easily observed ways (e.g. by school size or type, city size, local weather). This may be of great interest to policymakers, who are likely to be more interested in subsidizing the investment component of higher education rather than its consumption benefits.

\section{References}

Abbott, Brant, Giovanni Gallipoli, Costas Meghir, and Giovanni Violante. 2019. "Education policy and intergenerational transfers in equilibrium." Journal of Political Economy 127 (6):2569-2624.

Aguiar, Mark and Erik Hurst. 2005. "Consumption versus expenditure." Journal of Political Economy 113 (5):919-948.

. 2007. "Life-cycle prices and production." American Economic Review 97 (5):15331559.

Altonji, Joseph G and Lewis M Segal. 1996. "Small-sample bias in GMM estimation of covariance structures." Journal of Business 8 Economic Statistics 14 (3):353-366.

Arcidiacono, Peter. 2004. "Ability sorting and the returns to college major." Journal of Econometrics 121 (1-2):343-375.

Barsky, Robert, John Bound, Kerwin Charles, and Joseph P Lupton. 2002. "Accounting for the Black-White Wealth Gap: A Nonparametric Approach." Journal of the American Statistical Association 97 (459):663-673.

Barsky, Robert B, F Thomas Juster, Miles S Kimball, and Matthew D Shapiro. 1997. "Preference parameters and behavioral heterogeneity: An experimental approach in the health and retirement study." Quarterly Journal of Economics 112 (2):537-579.

Blundell, Richard, Luigi Pistaferri, and Ian Preston. 2008. "Consumption inequality and partial insurance." American Economic Review 98 (5):1887-1921. 
Browning, Martin and Thomas F Crossley. 2001. "The life-cycle model of consumption and saving." Journal of Economic Perspectives 15 (3):3-22.

Browning, Martin, Lars Peter Hansen, and James J Heckman. 1999. "Micro data and general equilibrium models." Handbook of Macroeconomics 1:543-633.

Crossley, Thomas F and Hamish W Low. 2014. "Job loss, credit constraints, and consumption growth." Review of Economics and Statistics 96 (5):876-884.

Cunha, Flavio, James Heckman, and Salvador Navarro. 2005. "Separating uncertainty from heterogeneity in life cycle earnings." Oxford Economic papers 57 (2):191-261.

Delavande, Adeline and Basit Zafar. 2019. "University choice: The role of expected earnings, nonpecuniary outcomes, and financial constraints." Journal of Political Economy 127 (5):2343-2393.

Dominitz, Jeff. 1998. "Earnings expectations, revisions, and realizations." Review of Economics and Statistics 80 (3):374-388.

Gemici, Ahu and Matthew Wiswall. 2014. "Evolution of gender differences in post-secondary human capital investments: College majors." International Economic Review 55 (1):2356.

Guo, Naijia and Charles Ka Yu Leung. 2020. "Do elite colleges matter? The impact of elite college attendance on entrepreneurship decisions and career dynamics." Global Research Unit Working Paper.

Hai, Rong and James J Heckman. 2017. "Inequality in human capital and endogenous credit constraints." Review of Economic Dynamics 25:4-36.

Hartocollis, Anemona. 2020. "Fever check and college dorms: the full college experience." New York Times (https://www.nytimes.com/2020/05/19/us/college-fall-2020coronavirus.html).

Hastings, Justine S, Christopher A Neilson, Anely Ramirez, and Seth D Zimmerman. 2016. "(Un) informed college and major choice: Evidence from linked survey and administrative data." Economics of Education Review 51:136-151.

Heckman, James J, Lance J Lochner, and Petra E Todd. 2006. "Earnings functions, rates of return and treatment effects: The Mincer equation and beyond." Handbook of the Economics of Education 1:307-458.

Jacob, Brian, Brian McCall, and Kevin Stange. 2018. "College as country club: Do colleges cater to students' preferences for consumption?" Journal of Labor Economics 36 (2):309348. 
Johnson, Matthew T. 2013. "Borrowing constraints, college enrollment, and delayed entry." Journal of Labor Economics 31 (4):669-725.

Kaplan, Greg. 2012. "Moving back home: Insurance against labor market risk." Journal of Political Economy 120 (3):446-512.

Keane, Michael P and Kenneth I Wolpin. 1997. "The career decisions of young men." Journal of Political Economy 105 (3):473-522.

- 2001. "The effect of parental transfers and borrowing constraints on educational attainment." International Economic Review 42 (4):1051-1103.

Lazear, Edward. 1977. "Education: Consumption or production?" Journal of Political Economy 85 (3):569-597.

Lochner, Lance and Alexander Monge-Naranjo. 2012. "Credit constraints in education." Annual Review of Economics 4 (1):225-256.

Meghir, Costas and Luigi Pistaferri. 2011. "Earnings, consumption and life cycle choices." In Handbook of Labor Economics, vol. 4. Elsevier, 773-854.

Oliver, Melvin L. and Thomas Shapiro. 1997. "Black Wealth/White Wealth: A New Perspective on Racial Inequality." Science and Society 61 (4):572-575.

Rask, Kevin. 2010. "Attrition in STEM fields at a liberal arts college: The importance of grades and pre-collegiate preferences." Economics of Education Review 29 (6):892-900.

Stinebrickner, Ralph and Todd Stinebrickner. 2003. "Working during school and academic performance." Journal of Labor Economics 21 (2):473-491.

- 2008a. "The causal effect of studying on academic performance." BE Journal of Economic Analysis \& Policy 8 (1).

- 2008b. "The effect of credit constraints on the college drop-out decision: A direct approach using a new panel study." American Economic Review 98 (5):2163-84.

. 2012. "Learning about academic ability and the college dropout decision." Journal of Labor Economics 30 (4):707-748.

- 2014. "Academic performance and college dropout: Using longitudinal expectations data to estimate a learning model." Journal of Labor Economics 32 (3):601-644.

Stinebrickner, Ralph, Todd Stinebrickner, and Paul Sullivan. 2019. "Job Tasks, Time Allocation, and Wages." Journal of Labor Economics 37 (2):399-433.

Wiswall, Matthew and Basit Zafar. 2015. "How do college students respond to public information about earnings?" Journal of Human Capital 9 (2):117-169. 
Zafar, Basit. 2013. "College major choice and the gender gap." Journal of Human Resources 48 (3):545-595. 


\section{Appendices}

\section{A Data Issues}

\section{A.1 Estimating Average Housing and Groceries Consumption for Graduates living with Parents}

Many Berea graduates that live at home with their parents report very low expenditures on food and housing, likely reflecting sizable in-kind transfers from their parents. To better account for these in-kind transfers, we use data on total household expenditures for similar families, adjusting for family size, to impute food and housing amounts when reported values in the BPS are low.

This analysis first uses the Consumer Expenditure Survey (CES) from 2003-2007 to estimate the average food and housing consumption for college graduates living with their parents. We restrict this analysis to CES respondents with at least one child in the household who (i) is aged 22-29 years old, (ii) is not currently enrolled in school, and (iii) has a college degree. For each household, we use information on (i) household expenditures on various categories of consumption goods, (ii) number of household members, (iii) total household income, (iv) salary of each household member, and (v) location of the household.

For each of the 244 22-29 year-old household members in this sample, we first measure total household food and housing consumption using reported expenditures on food, rent (or equivalent rent for home-owners), and other home services. We then divide this householdlevel consumption by the number of members in the household to obtain individual-level measures of food and housing consumption. We also obtain a measure of parental income by subtracting total salaries earned by young members in the household from total household income.

Next, we regress individual food and housing consumption on parental income, the youth's own salary, and a location dummy that takes the value of 1 if the household is in the South Census Region (excluding Washington DC) or a neighboring state of Kentucky. ${ }^{43}$ We use these regression coefficients to obtain predicted post-college food and housing consumption values for Berea graduates living with their parents (at $t=G+1$ ) using annual parental

\footnotetext{
${ }^{43}$ Besides Kentucky, this location dummy covers the following states: Delaware, Florida, Georgia, Maryland, North Carolina, South Carolina, Virginia, West Virginia, Alabama, Mississippi, Tennessee, Arkansas, Louisiana, Oklahoma, Texas, Indiana, Ohio, and Illinois.
} 
income reported during college and $W_{G+1}$, letting the location dummy take the value of 1 . The average of this CES-based measure for the 151 students in our post-college sample is $\$ 7,220$, which is about $\$ 900$ more than the total annual value for food and housing during college, $C^{f h}=\$ 6,350$.

Finally, our baseline analysis only imputes total food and housing expenditures using this CES-based amount for Berea graduates living with their parents if their total post-college consumption on food and housing (as reported in the BPS survey) is lower. Based on this criteria, we impute food and housing expenditures for 53 of the 56 graduates who are living with their parents in year $t=G+1$.

\section{A.2 Descriptive Statistics for Second-Year Data}

Table 7 reports descriptive statistics for second-year in-school consumption expenditures, desired additional borrowing, and beliefs about post-college earnings.

Table 7: Second-Year Consumption, Desired Borrowing, and Beliefs in BPS

\begin{tabular}{lccccc}
\hline & $C_{2}^{\text {oth }}$ & $\hat{\delta}_{2}$ & $\hat{\delta}_{2}($ if $>0)$ & $Q_{2, G+1}^{2}($ Median $)$ & $\underline{W}_{2, G+1}($ Min $)$ \\
\hline Mean & 0.78 & 0.31 & 1.17 & 39.57 & 27.22 \\
Std. Dev. & 0.80 & 0.72 & 0.99 & 25.60 & 21.54 \\
Median & 0.49 & 0.00 & 0.99 & 34.48 & 24.63 \\
Interquart. Range & 0.69 & 0.25 & 1.13 & 19.70 & 10.59 \\
Sample Size & 155 & 155 & 41 & 155 & 155 \\
\hline
\end{tabular}

Notes: All values in thousands of year 2001 U.S. dollars. $C_{2}^{\text {oth }}$ represents reported annual consumption expenditures (excluding room, board, and textbooks) during the second year of college. $\hat{\delta}_{2}$ represents the amount of additional loan a student is willing to take in the hypothetical borrowing scenario during the second year of college. $Q_{2, G+1}^{2}$ and $\underline{W}_{2, G+1}$ are the median and minimum of reported subjective earnings distributions during the second year of college, respectively.

\section{A.3 Descriptive Statistics for Post-College Consumption by Cat- egory}

Table 8 reports descriptive statistics for post-college consumption expenditures by category. 
Table 8: Descriptive Statistics for Post-college Consumption by Category

\begin{tabular}{lcccc}
\hline & & Standard & & Interquartile \\
& Mean & Deviation & Median & Range \\
\hline Rent (inc. Utilities) & 3.11 & 2.92 & 3.18 & 5.05 \\
Groceries & 1.18 & 0.95 & 1.06 & 1.06 \\
Rent (inc. Utilities) + Groceries & 4.29 & 3.42 & 4.34 & 5.29 \\
Adjusted Food and Housing & 6.32 & 2.57 & 6.79 & 2.18 \\
Telephone & 0.64 & 0.43 & 0.58 & 0.41 \\
Car and Travel & 2.86 & 3.35 & 2.11 & 2.65 \\
Recreation and Entertainment & 1.12 & 1.60 & 0.53 & 0.74 \\
Clothing and Other Personal & 0.72 & 0.79 & 0.53 & 0.84 \\
Music, Computers, TV, and Other Electronics & 0.27 & 1.17 & 0.00 & 0.16 \\
Medical and Dental, Other than Insurance & 0.30 & 1.06 & 0.00 & 0.16 \\
Health Insurance & 0.82 & 6.98 & 0.00 & 0.31 \\
Total Other Spending & 1.36 & 4.16 & 0.00 & 1.05 \\
\hline
\end{tabular}

Notes: Consumption measures based on main post-college sample of 151 students. All categories based on direct survey responses, except for 'Adjusted Food and Housing', which adjusts 'Rent (inc. Utilities) + Groceries' for graduates living with parents who report lower amounts than imputed from Consumer Expenditure Survey (see Appendix A.1). All values in thousands of year 2001 U.S. dollars.

\section{A.4 Descriptive Statistics for Student Characteristics}

Table 9 describes student characteristics for our main in-school and post-college samples. Table 10 reports these statistics for broader samples that include married students and those who are considered "debt averse" based on their answers to question Q.1.B of the BPS.

\section{B After-Tax Earnings}

After-tax earnings are computed using 2001 federal and Kentucky state tax schedules for single individuals without children. An individual with before-tax earnings $w$ needs to pay FICA, $F I C A(w)$, federal tax, $F T(w)$, and state tax, $S T(w)$, and receives state income credit $\operatorname{SIC}(w)$. Formally, after-tax earnings $\psi(w)$ is given by:

$$
\psi(w)=w-F I C A(w)-F T(w)-S T(w)+S I C(w),
$$

where $\operatorname{FICA}(w)=0.062 \cdot \min \{w, \$ 80400\}$ and other taxes/credits are determined as follows. To compute federal and state taxes, we first subtract deductions and exemptions from $w$ to 
Table 9: Descriptive Statistics for Student Characteristics

\begin{tabular}{lcccc}
\hline & Male & Black & High School GPA & Family Income \\
\hline A) Main In-school Sample (177 & students) \\
Mean & 0.17 & 0.49 & 3.40 & 26.16 \\
Std. Dev. & 0.38 & 0.50 & 0.50 & 19.33 \\
Median & 0.00 & 0.00 & 3.50 & 27.24 \\
Interquart. Range & 0.00 & 1.00 & 0.70 & 32.23 \\
\multicolumn{5}{l}{ B) Main Post-college Sample } \\
Mean & 0.19 & 0.30 & 3.49 & \\
Std. Dev. & 0.40 & 0.46 & 0.45 & 27.75 \\
Median & 0.00 & 0.00 & 3.62 & 18.37 \\
Interquart. Range & 0.00 & 1.00 & 0.68 & 28.64 \\
\hline
\end{tabular}

Notes: Family income in thousands of year 2001 U.S. dollars.

Table 10: Descriptive Statistics for Student Characteristics (Full Samples)

\begin{tabular}{lcccc}
\hline & Male & Black & High School GPA & Family Income \\
\hline A) Full In-School Sample (300 & students) & \\
Mean & 0.16 & 0.44 & 3.39 & 25.40 \\
Std. Dev. & 0.37 & 0.50 & 0.47 & 17.78 \\
Median & 0.00 & 0.00 & 3.50 & 25.53 \\
Interquart. Range & 0.00 & 1.00 & 0.71 & 28.63 \\
B) Expanded Post-College Sample & $\mathbf{( 1 9 4}$ students) \\
Mean & 0.15 & 0.31 & 3.50 & 27.78 \\
Std. Dev. & 0.36 & 0.47 & 0.43 & 17.68 \\
Median & 0.00 & 0.00 & 3.60 & 28.89 \\
Interquart. Range & 0.00 & 1.00 & 0.68 & 26.00 \\
\hline
\end{tabular}

Notes: Compared to the main in-school sample, the full in-school sample also includes those who would reject an additional loan due to debt-aversion. Compared to the main post-college sample, the expanded post-college sample also includes those who were married. Family income in thousands of year 2001 U.S. dollars. 
Table 11: Federal and Kentucky Income Tax Brackets in 2001

\begin{tabular}{cc|cc}
\hline \multicolumn{2}{c|}{ Federal Taxes } & \multicolumn{2}{c}{ Kentucky Taxes } \\
Tax Rate & Taxable Earnings & Tax Rate & Taxable Earnings \\
\hline $15 \%$ & $(\$ 0, \$ 27,050]$ & $2 \%$ & $(\$ 0, \$ 3,000]$ \\
$27.5 \%$ & $(\$ 27,050, \$ 65,550]$ & $3 \%$ & $(\$ 3,000, \$ 4,000]$ \\
$30.5 \%$ & $(\$ 65,550, \$ 136,750]$ & $4 \%$ & $(\$ 4,000, \$ 7,000]$ \\
$35.5 \%$ & $(\$ 136,750, \$ 297,350]$ & $5 \%$ & $(\$ 7,000, \$ 8,000]$ \\
$39.1 \%$ & $(\$ 297,350, \infty]$ & $6 \%$ & $(\$ 8,000, \infty]$ \\
\hline
\end{tabular}

Source: Internal Revenue Service and Kentucky Department of Revenue.

obtain taxable earnings. The federal standard deduction and exemption are $\$ 4,550$ and $\$ 2,900$ in 2001 . The state standard deduction for Kentucky is $\$ 1,700$. We then apply the income tax brackets shown in Table 11 to taxable earnings to compute $F T(w)$ and $S T(w)$. The state income credit for Kentucky is $\$ 20$.

\section{Estimating the Autocorrelation in Log Wage Shocks}

In this appendix, we estimate the autocorrelation parameter for wage shocks, $\Gamma$, using data on the students' realized annual earnings in the post-college periods.

We assume that wages for individual $i$ in year $t$ are given by

$$
\log \left(W_{i t}\right)=\mathbf{x}_{i}^{\prime} \phi+g_{t}+\alpha_{i}+\sigma_{t} \epsilon_{i t} \quad \forall i \text { and } \forall t \geq G+1,
$$

allowing for observable and unobservable heterogeneity in mean log earnings. Observed characteristics are reflected in the vector $\mathbf{x}_{i}$, which includes gender, race, high school GPA, and ACT scores. Permanent unobserved individual differences are captured by $\alpha_{i} \Perp \mathbf{x}_{i}$, while year dummies $g_{t}$ capture both time and age/experience effects. We assume that $\epsilon_{i t}$ has zero mean, unit variance, and is uncorrelated with $\left(\mathbf{x}_{i}, g_{t}, \alpha_{i}\right)$. We are interested in estimating the serial correlation in $\epsilon_{i t}$ given by $\Gamma$.

To estimate $\Gamma$ (as well as $\sigma_{\alpha}^{2} \equiv \operatorname{Var}\left(\alpha_{i}\right)$ and all $\sigma_{t}$ ), we first regress $\log \left(W_{i t}\right)$ on $\mathbf{x}_{i}$ and $g_{t}$ to obtain residuals: $y_{i t} \equiv \alpha_{i}+\sigma_{t} \epsilon_{i t}$. Next, we use the Minimum Distance (MD) estimator that minimizes the distance between empirical and theoretical second moments for $y_{i t}$, where the covariance between $y_{i t}$ and $y_{i t+k}$ is

$$
\operatorname{cov}\left(y_{i, t}, y_{i t+k}\right)=\sigma_{\alpha}^{2}+\sigma_{t} \sigma_{t+k} \Gamma^{k} .
$$

Collect all parameters to be estimated in $\theta \equiv\left(\Gamma, \sigma_{\alpha}^{2}, \sigma_{5}^{2}, \ldots, \sigma_{12}^{2}\right)$. Denote the theoretical co-variance matrix implied by $\theta$ as $M(\theta)$, and define $\mathbf{m} \equiv \operatorname{vech}(M)$, the stacked vector of 
unique moments in $M(\theta)$. Given that our panel consists of 8 periods, we have 10 parameters and 36 unique moments.

In order to handle missing observations (for some person-years), we adopt the notation used in Blundell, Pistaferri, and Preston (2008). Denote

$$
\mathbf{y}_{\mathbf{i}}=\left\{\begin{array}{c}
y_{i, 5} \\
y_{i, 6} \\
\ldots \\
y_{i, 12}
\end{array}\right\} \quad \text { and } \quad \mathbf{d}_{\mathbf{i}}=\left\{\begin{array}{c}
d_{i, 5} \\
d_{i, 6} \\
\ldots \\
d_{i, 12}
\end{array}\right\}
$$

where $y_{i t}=d_{i t}=0$ if student $i$ is not observed in period $t$ and $d_{i t}=1$ if student $i$ is observed in period $t$. Then, sample moments $\hat{\mathbf{m}}$ satisfy

$$
\hat{\mathbf{m}}=\operatorname{vech}\left\{\left(\sum_{i=1}^{N} \mathbf{y}_{\mathbf{i}} \mathbf{y}_{\mathbf{i}}^{\prime}\right) \oslash\left(\sum_{i=1}^{N} \mathbf{d}_{\mathbf{i}} \mathbf{d}_{\mathbf{i}}^{\prime}\right)\right\},
$$

where $\oslash$ is element-wise division.

The MD estimator $\hat{\theta}$ is defined as follows:

$$
\hat{\theta}=\min _{\theta}(\hat{\mathbf{m}}-\mathbf{m}(\theta))^{\prime} \Omega(\hat{\mathbf{m}}-\mathbf{m}(\theta))
$$

where $\Omega$ is the weighting matrix. We use the identity matrix instead of the estimated 'optimal' weighting matrix, since the latter tends to create significant small sample bias (Altonji and Segal, 1996). We estimate $\Gamma=0.6165$.

\section{Estimating $\bar{D}$ and Post-College Beliefs}

This appendix provides details on the estimation of $\bar{D}$ in the MB Approach.

\section{D.1 Determining $\bar{D}$}

As discussed in Section 5 of the paper, we estimate $\bar{D}$ by equating the sample average of period $G+1$ consumption, $C_{G+1}$, with its counterpart solution to the lifecycle consumption problem in equation (9) using period $G+1$ beliefs, $\tilde{C}\left(D_{G+1}, W_{G+1} ; \bar{D},\left\{F_{G+1}^{W_{t}}\right\}_{t=G+2}^{T}\right)$. Specifically, $\bar{D}$ solves

$$
\frac{1}{N} \sum_{i=1}^{N} C_{i, G+1}=\frac{1}{N} \sum_{i=1}^{N} \tilde{C}_{i}\left(D_{i, G+1}, W_{i, G+1} ; \bar{D},\left\{F_{i, G+1}^{W_{t}}\right\}_{t=G+2}^{T}\right)
$$


where we include $i$ subscripts to reflect student-specific variables/distributions from our main in-school sample. (The post-college consumption function implicitly depends on studentspecific values for $\beta$ and $\rho$ as well.)

It is important to note that students' beliefs about lifecycle earnings may change between the time they start school and graduate. That is, $\left\{F_{G+1}^{W_{t}}\right\}_{t=G+2}^{T}$ need not be the same as $\left\{F_{1}^{W_{t}}\right\}_{t=G+2}^{T}$. We allow these distributions to differ; however, we assume in both cases that individuals believe that annual earnings are characterized by a shifted log-normal distribution governed by parameters $\left(\underline{W}_{j, t}, \mu_{j . t}, \sigma_{j, t}\right)$ for $j \in\{1, G+1\}$. Section 5 of the paper shows how we use beliefs elicited during the first year of college (about earnings distributions in periods $G+1, G+6$, and $G+16)$ to determine $\left\{F_{1}^{W_{t}}\right\}_{t=G+2}^{T}$.

We take a similar approach to beliefs after graduation; however, these beliefs were elicited differently and require a slightly more complicated approach. In particular, the BPS postcollege survey asked respondents to report the probabilities that their household income in one year $(t=G+2)$ and in five years $(t=G+6)$ would fall in each of ten mutually exclusive income intervals. The respondents also reported the probabilities that they would be married in one year and five years, respectively.

Section D.2 of this appendix describes our approach for obtaining post-college beliefs $F_{G+1}^{W_{t}}$ about future own earnings for $t=G+2$ and $t=G+6$ (i.e., ages 24 and 28, respectively) from reported beliefs about future household income and marriage. Similar to our treatment of in-school beliefs, we assume that the distributional parameters $\underline{W}_{G+1, t}, \mu_{G+1, t}$, and $\sigma_{G+1, t}$ grow linearly between periods $G+2$ and $G+6$ and then again between periods $G+6$ and $G+16$, remaining constant after period $G+16$ (i.e., age 38 ). Since we do not have information on post-college beliefs about income in period $G+16$, we assume that the growth in each distributional parameter $\left(\underline{W}_{G+1, t}, \mu_{G+1, t}, \sigma_{G+1, t}\right)$ between periods $G+6$ and $G+16$ is the same as the average growth in these parameters based on beliefs elicited during the first year of college (e.g., $\left.\mu_{i, G+1, G+16}-\mu_{i, G+1, G+6}=N^{-1} \sum_{i=1}^{N}\left(\mu_{i, 1, G+16}-\mu_{i, 1, G+6}\right)\right){ }^{44}$

\footnotetext{
${ }^{44}$ We do not use student-specific growth from first-year beliefs to impute growth in post-college beliefs, because we do not have first-year beliefs for many individuals in the post-college sample used here. Appendix H.5 instead explores the case where we use average growth rates in $\left(\underline{W}_{1, t}, \mu_{1, t}, \sigma_{1, t}\right)$ between periods $t=G+6$ and $t=G+16$ to impute post-college period $G+16$ beliefs.
} 


\section{D.2 Post-college Beliefs about Future Own Earnings}

The BPS post-college survey contains questions eliciting respondents' beliefs about future family income using a probability format. Specifically, the post-college survey questions elicited the perceived probability that a respondent's annual family income in the next year (and in five years) would fall in each of ten income intervals, $K_{j}$, for $j=1,2, \ldots, 10{ }^{45} \mathrm{We}$ denote the reported probability associated with category $K_{j}$ as $P_{j, t}^{K}$. The BPS also elicited respondents' post-college perceived probabilities of being married in the next year (and in five years), which we denote by $P_{t}^{M}$. ${ }^{46}$

We now describe how we obtain a respondent's period $G+1$ beliefs about own earnings in future year $t, F_{G+1}^{W_{t}}$, which are characterized by $\left(\underline{W}_{G+1, t}, \mu_{G+1, t}, \sigma_{G+1, t}\right)$, from $P_{j, t}^{K}$ and $P_{t}^{M}$. We denote a respondent's annual family income at year $t$ as $W_{F, t}$ and denote the annual earnings of her spouse (if present) as $W_{S, t}$. Let $M_{t}$ denote the respondent's marital status at year $t$ with $M_{t}=1$ if the respondent is married and $M_{t}=0$ otherwise. Then, $W_{F, t}=W_{t}+M_{t} \cdot W_{S, t}$.

Consistent with the notion of assortative mating, we assume that Berea graduates marry someone who draws from the same earnings distribution as themselves (based on their subjective beliefs), so beliefs about $W_{t}$ and $W_{S, t}$ are identically distributed. For tractability, we further assume that individuals believe that spousal earnings realizations are independent of their own and that marriage is independent of earnings. Under these assumptions, it is straightforward to obtain the probability that $W_{F, t}$ falls in income category $K_{j}$, $j=1,2, \ldots, 10$, for parameters $\left(\underline{W}_{G+1, t}, \mu_{G+1, t}, \sigma_{G+1, t}\right)$ and perceived marriage probability $P_{t}^{M}$. We denote this probability as $\tilde{P}_{j, t}^{K}\left(\underline{W}_{G+1, t}, \mu_{G+1, t}, \sigma_{G+1, t} ; P_{t}^{M}\right)$.

In the absence of any measurement error, for any period $t$, the reported probability that income falls in interval $K_{j, t}, P_{j, t}^{K}$, should equal the implied probability $\tilde{P}_{j, t}^{K}\left(\underline{W}_{G+1, t}, \mu_{G+1, t}, \sigma_{G+1, t} ; P_{t}^{M}\right)$ for all $j$. This suggests that $\left(\underline{W}_{G+1, t}, \mu_{G+1, t}, \sigma_{G+1, t}\right)$ should be chosen to minimize the difference between $P_{j, t}^{K}$ and $\tilde{P}_{j, t}^{K}\left(\underline{W}_{G+1, t}, \mu_{G+1, t}, \sigma_{G+1, t} ; P_{t}^{M}\right)$.

Also note that $P_{j, t}^{K}$ imposes additional restrictions on $\underline{W}_{G+1, t}$ : If $K_{j}$ is the smallest income category on which a respondent assigns positive probability, we know that the lower bound of $W_{F, t}$ should be no less than $\min \left(K_{j}\right)$. Moreover, $\min \left\{\min \left(K_{j}\right) \mid P_{j, t}^{K}>0\right\}$ is the minimum of

\footnotetext{
${ }^{45}$ The ten income intervals are $[\$ 0, \$ 15,000),[\$ 15,000, \$ 30,000),[\$ 30,000, \$ 45,000),[\$ 45,000, \$ 60,000)$, $[\$ 60,000, \$ 75,000),[\$ 75,000, \$ 90,000),[\$ 90,000, \$ 105,000),[\$ 105,000, \$ 120,000),[\$ 120,000, \$ 135,000)$, and $[\$ 135,000,1$ million).

${ }^{46}$ The average perceived probability of marriage is about $40 \%$ for one-year ahead beliefs (age 24 ) and $70 \%$ for five-year ahead beliefs (age 28).
} 
the smallest income interval on which a respondent assigns positive probability. Therefore, $\underline{W}_{G+1, t} \geq \min \left\{\min \left(K_{j}\right) \mid P_{j, t}^{K}>0\right\}$ if $P_{t}^{M}<1$, and $\underline{W}_{G+1, t} \geq \frac{1}{2} \min \left\{\min \left(K_{j}\right) \mid P_{j, t}^{K}>0\right\}$ if $P_{t}^{M}=1$.

Formally, $\left(\underline{W}_{G+1, t}, \mu_{G+1, t}, \sigma_{G+1, t}\right)$ is chosen as follows:

$$
\begin{aligned}
\left(\widehat{W}_{G+1, t}, \hat{\mu}_{G+1, t}, \hat{\sigma}_{G+1, t}\right)= & \min _{\left(\underline{W}_{G+1, t}, \mu_{G+1, t}, \sigma_{G+1, t}\right)} \sum_{j}\left[P_{j, t}^{K}-\tilde{P}_{j, t}^{K}\left(\underline{W}_{G+1, t}, \mu_{G+1, t}, \sigma_{G+1, t} ; P_{t}^{M}\right)\right]^{2} \\
& \text { s.t. } \underline{W}_{G+1, t} \geq \frac{1}{1+\mathbb{1}\left(P_{t}^{M}=1\right)} \min \left\{\min \left(K_{j}\right) \mid P_{j, t}^{K}>0\right\} \text { and } \sigma_{G+1, t}>0,
\end{aligned}
$$

where $\mathbb{1}(\cdot)$ is the indicator function. We numerically solve this problem for each of the 151 respondents in the post-college sample using simulation-based methods.

\section{H Additional Robustness}

Recall that our main estimates of $\mathcal{V}$ reported in the paper average $\$ 11,680$ and $\$ 15,110$ for the DD and MB Approaches, respectively. Table 12 reports the distribution for estimated $\mathcal{V}$ under a variety of alternative assumptions. All of these results suggest substantial and heterogeneous consumption values of college.

\section{H.1 Estimates for the Full Sample}

Panel A of Table 12 shows that expanding our sample to include all students who answered survey question Q.1 (including those who would reject an additional loan due to reasons other than consumption smoothing) yields average consumption values $\mathcal{V}$ of $\$ 11,870$ for the DD Approach and $\$ 15,100$ for the MB Approach.

\section{H.2 Alternative Approaches for Addressing Missing $D_{G+1}$}

In our baseline DD analysis, we use average post-college debt from our sample to impute any missing $D_{G+1}$ observations when estimating $\tilde{C}_{G+1}$. Here, we explore two alternatives. First, we simply exclude any students who did not report $D_{G+1}$ from our sample when estimating $\tilde{C}(\cdot, \cdot)$. Second, we explore an alternative imputation method that takes into account observed heterogeneity in $D_{G+1}$. Specifically, we first estimate $D_{G+1}$ as a linear function of gender, race, high school GPA, and family income (in the first year of college), then use the estimated function to impute $D_{G+1}$ for students with missing $D_{G+1}$ data. Among the four regressors, we find that family income is the only one that has a statistically significant (at a 
Table 12: Distribution for $\mathcal{V}$ (in $\$ 1,000$ s) under Alternative Assumptions

\begin{tabular}{|c|c|c|c|c|}
\hline & Mean & 25th Perc. & Median & 75th Perc. \\
\hline \multicolumn{5}{|c|}{ A) Full In-School Sample (Includes Debt-Averse Students) } \\
\hline DD Approach & 11.87 & 8.04 & 10.69 & 14.14 \\
\hline MB Approach & 15.10 & 4.10 & 11.07 & 23.62 \\
\hline \multicolumn{5}{|c|}{ B) Alternative Approaches for Addressing Missing $D_{G+1}$} \\
\hline Excluding Students with Missing $D_{G+1}$ (DD Approach) & 11.66 & 7.82 & 11.05 & 14.09 \\
\hline Imputation using Background Char. (DD Approach) & 11.74 & 7.98 & 10.92 & 13.87 \\
\hline Imputation using Background Char. (MB Approach) & 15.11 & 4.14 & 11.13 & 23.97 \\
\hline \multicolumn{5}{|c|}{ C) Alternative Interpretation of Non-Employment Periods } \\
\hline Unemployed Fraction $P_{t}^{U}$ of Year (DD Approach) & 10.63 & 7.23 & 10.13 & 12.94 \\
\hline Unemployed Fraction $P_{t}^{U}$ of Year (MB Approach) & 13.59 & 3.08 & 9.98 & 22.69 \\
\hline \multicolumn{5}{|c|}{ D) Alternative Value for Earnings Autocorrelation } \\
\hline$\Gamma=0.9(\mathrm{MB}$ Approach $)$ & 14.59 & 3.63 & 11.00 & 23.59 \\
\hline \multicolumn{5}{|l|}{ E) Alternative Imputation Method for $F_{G+1}^{W_{t+16}}$} \\
\hline MB Approach & 16.45 & 4.21 & 12.06 & 26.05 \\
\hline \multicolumn{5}{|l|}{ F) Using Second Year In-College Data } \\
\hline DD Approach & 11.00 & 7.27 & 9.49 & 12.21 \\
\hline MB Approach & 13.69 & 4.58 & 10.29 & 20.61 \\
\hline
\end{tabular}

Notes: Results in Panel A for full in-school sample are based on 300 students responding to baseline survey. All other results are based on main in-school sample with 1 ry observations. 
$5 \%$ level) relationship with $D_{G+1}$. One dollar increase in annual family income is associated with a 9.4 cent increase in end-of-college debt $D_{G+1}$. In both cases, we obtain alternative estimates for $\tilde{C}(\cdot, \cdot)$ to be used in applying the DD Approach. We also consider the alternative imputation approach for $D_{G+1}$ (based on background characteristics) to apply our MB Approach.

As reported in Panel B of Table 12, in all cases, the distributions for $\mathcal{V}$ are nearly identical to the analogous baseline estimated distributions.

\section{H.3 Alternative Assumptions about Expected Unemployment Spells}

In Sections 4.3.3 and 5.4.2 of the paper, we consider the possibility that students report beliefs about the distribution of post-college earnings conditional on working. In doing so, we take advantage of students' perceived probability of not working in future periods, $P_{t}^{U}$. Our robustness analysis in the paper takes a very conservative approach, assuming that $P_{t}^{U}$ represents the probability that a student is non-employed for the entire year $t$. In this appendix section, we instead assume that $P_{t}^{U}$ reflects the fraction of year $t$ that a student expects to be non-employed. This assumption is more aligned with the fact that unemployment spells typically last only a couple months. In this case, a student's unconditional subjective earnings distribution, $F_{1}^{W_{t}}$, can be easily obtained by multiplying each realization of the reported subjective (conditional) earnings distribution, $\underline{F}_{1}^{W_{t}}$, by the factor $1-P_{t}^{U}$, since $F_{1}^{W_{t}}\left(\left(1-P_{t}^{U}\right) w\right)=\underline{F}_{1}^{W_{t}}(w) .{ }^{47}$ With this simple adjustment used in calculating the expected marginal utility of post-college consumption, the DD Approach produces $\mathcal{V}$ values that are only about $\$ 1,000$ lower than the baseline DD estimates. See Panel C of Table 12.

In estimating $\mathcal{V}$ using the MB Approach, we apply the same adjustment to reported beliefs as above; however, we must do this for all years $t=G+1, \ldots, T{ }^{48}$ With this adjustment to beliefs, we follow the same MB Approach as used in the paper, which yields a distribution for $\mathcal{V}$ shifted leftward by $\$ 1,000-1,500$ compared to the baseline MB distribution. (See Panel C of Table 12.) If we further assume that individuals receive unemployment insurance benefits

\footnotetext{
${ }^{47}$ This approach abstracts from any unemployment insurance individuals may expect to receive. In estimating $\tilde{C}(\cdot, \cdot)$, this approach also implicitly assumes that individuals who are working at the time of the survey do not experience any periods of unemployment over the year. Both of these assumptions imply that we obtain conservative estimates of $\mathcal{V}$.

${ }^{48}$ We take the same approach as described in Section 5.4 .2 of the paper to obtain $P_{t}^{U}$ for all years using freshman year elicited beliefs about $P_{t}^{U}$ for years $t=G+1, t=G+6$, and $t=G+16$.
} 
of $\$ 234$ /week (for up to 26 weeks) when non-employed, then the sample average for $\mathcal{V}$ is only about $\$ 900$ less than the MB baseline average. ${ }^{49}$

\section{H.4 Alternative Earnings Autocorrelation}

Our main analysis using the MB Approach assumes that students' perceived value of $\Gamma$ equals 0.62 , as estimated from realized earnings reported in the post-college portion of the BPS. The literature on earnings dynamics estimates a broad range for this parameter, which sometimes includes much higher values (Meghir and Pistaferri, 2011). Panel D of Table 12 shows that setting $\Gamma=0.9$ produces a slightly lower $\mathcal{V}$ than its counterpart reported in Section 5.

\section{H.5 Alternative Imputation Method for Post-College Beliefs about $W_{G+16}$}

Recall that, for the MB Approach, we need information about students' post-college beliefs about future earnings, in order to identify the additional borrowing limit $\bar{D}$. The post-college data contains information about beliefs at $t=G+1$ about $W_{G+2}$ and $W_{G+6}$, but does not have this information about $W_{G+16}$. In the baseline, we assume that the growth in each distributional parameter $\left(\underline{W}_{G+1, t}, \mu_{G+1, t}, \sigma_{G+1, t}\right)$ between periods $G+6$ and $G+16$ is the same as the average growth in these parameters based on beliefs elicited during the first year of college (e.g., $\left.\mu_{i, G+1, G+16}-\mu_{i, G+1, G+6}=N^{-1} \sum_{i=1}^{N}\left(\mu_{i, 1, G+16}-\mu_{i, 1, G+6}\right)\right)$.

Here, we consider an alternative imputation approach, assuming that individual growth rates in $\left(\underline{W}_{G+1, t}, \mu_{G+1, t}, \sigma_{G+1, t}\right)$ from $t=G+6$ to $t=G+16$ equal the corresponding growth rate in their sample averages based on in-school beliefs. We first compute the ratio of the sample average of $\underline{W}_{1, G+16}$ to the sample average of $\underline{W}_{1, G+6}$, the ratio of the sample average of $\mu_{1, G+16}$ to the sample average of $\mu_{1, G+6}$, and the ratio of the sample average of $\sigma_{1, G+16}$ to the sample average of $\sigma_{1, G+6}$. We then multiply these ratios by students' corresponding post-college belief measures $\underline{W}_{G+1, G+6}, \mu_{G+1, G+6}$, and $\sigma_{G+1, G+6}$ to impute the post-college values of $\underline{W}_{G+1, G+16}, \mu_{G+1, G+16}$, and $\sigma_{G+1, G+16}$. Finally, we use these values and the same assumptions in the text to re-estimate $\bar{D}$ and then the distribution of $\mathcal{V}$.

With this alternative imputation method for $F_{G+1}^{W_{G+16}}$, we estimate a much higher borrowing limit, $\bar{D}$ (roughly $\$ 36,000$ ). Panel $\mathrm{E}$ of Table 12 shows that the sample average of $\mathcal{V}$ is

\footnotetext{
${ }^{49}$ According to data from the Employment and Training Administration, the average weekly payment for unemployment insurance benefits in Kentucky was $\$ 234$ in 2001.
} 
$\$ 16,450$, about $\$ 1,300$ larger than the baseline estimate.

\section{H.6 Estimation Using Second-Year Data}

In the baseline, we quantify the consumption value of college using consumption expenditures in the first year of college and the expected marginal utility of consumption during the first year after college. Since all the relevant in-school survey questions were collected annually during college for the 2001 cohort, we can conduct the same analysis using data from later college years; although, we lose any college dropouts along the way. To examine the robustness of our results to the choice of in-school year, we re-do our analysis using second-year college data for the 2001 cohort. ${ }^{50}$

In the second year of college, 210 students gave valid responses to earnings expectations questions, the consumption expenditure question, and the hypothetical borrowing question. Among them, 155 students did not report debt-aversion as a reason to reject an additional loan. They form our main second-year sample.

Based on this second-year sample, we report the distribution of $\mathcal{V}$ obtained using the DD and MB Approaches in Panel $\mathrm{F}$ of Table 12. The estimates of $\mathcal{V}$ are only slightly smaller than their counterparts in the baseline analysis using data from students' first year at Berea.

To further explore the relationship between first- and second-year estimates at an individual level, we restrict our attention to the 89 students who are in both the main in-school (first-year) sample (177 students) and the second-year sample (155 students). The average $\mathcal{V}$ values for these 89 students are $\$ 11,310$ (DD Approach) and $\$ 14,430$ (MB Approach) based on the first-year data and $\$ 10,490$ (DD Approach) and $\$ 13,220$ (MB Approach) based on the second-year data. Additionally, the correlation between the first- and second-year estimates is 0.56 for the DD Approach and 0.76 for the MB Approach. Applying the Two-Sample Kolmogorov-Smirnov test separately for both the DD and MB Approaches, in neither case can we reject the null that the first- and second-year estimated $\mathcal{V}$ distributions are the same (based on a $5 \%$ significance level).

\footnotetext{
${ }^{50}$ We continue to focus on the 2001 cohort, because the hypothetical borrowing question is only available in the third year for the 2000 cohort.
} 


\section{Post-College Consumption Function Estimates for the DD Approach}

For the DD Approach, we estimate the following specification of $\tilde{C}\left(D_{G+1}, W_{G+1}\right)$ using constrained least squares:

$$
\tilde{C}\left(D_{G+1}, W_{G+1}\right)=\gamma_{0}+\gamma_{w, 1} W_{G+1}+\gamma_{w, 2} W_{G+1}^{2}+\gamma_{d, 1} D_{G+1}+\gamma_{d, 2} D_{G+1}^{2}+\gamma_{w, d} W_{G+1} D_{G+1} .
$$

Table 13 reports estimates for $\left(\gamma_{0}, \gamma_{w, 1}, \gamma_{w, d}\right)$, along with average derivatives for $\frac{\partial \tilde{C}\left(D_{G+1}, W_{G+1}\right)}{\partial W_{G+1}}$ and $\frac{\partial \tilde{C}\left(D_{G+1}, W_{G+1}\right)}{\partial D_{G+1}}$. Due to the constraints imposed on the signs of both $\frac{\partial \tilde{C}\left(D_{G+1}, W_{G+1}\right)}{\partial W_{G+1}}$ and $\frac{\partial \tilde{C}\left(D_{G+1}, W_{G+1}\right)}{\partial D_{G+1}}$, estimates of $\gamma_{w, 2}, \gamma_{d, 1}$, and $\gamma_{d, 2}$ are zero for all cases. When the point estimates of $\left(\gamma_{0}, \gamma_{w, 1}, \gamma_{w, d}\right)$ from an ordinary least squares (OLS) regression (with $W_{G+1}$ and $W_{G+1} D_{G+1}$ the only regressors) are identical to the corresponding estimates from constrained least squares, we report the standard errors from OLS in parentheses. If the two sets of point estimates are not identical, we report N.A.

Table 13: Alternative Post-College Consumption Function Estimates for the DD Approach

\begin{tabular}{|c|c|c|c|c|c|c|c|}
\hline & $\gamma_{0}$ & $\gamma_{w, 1}$ & $\gamma_{w, d}$ & Avg. $\frac{\partial \tilde{C}}{\partial W_{G+1}}$ & Avg. $\frac{\partial \dot{C}}{\partial D_{G+1}}$ & $R^{2}$ & $\mathrm{~N}$ \\
\hline Baseline & $\begin{array}{l}8.113 \\
(1.659)\end{array}$ & $\begin{array}{c}0.337 \\
(0.081)\end{array}$ & $\begin{array}{l}-0.004 \\
(0.006)\end{array}$ & 0.313 & -0.080 & 0.114 & 151 \\
\hline Excluding Individuals with Missing $D_{G+1}$ & $\begin{array}{l}7.545 \\
(1.906)\end{array}$ & $\begin{array}{c}0.350 \\
(0.091)\end{array}$ & $\begin{array}{l}-0.004 \\
(0.006)\end{array}$ & 0.326 & -0.080 & 0.123 & 118 \\
\hline Imputing $D_{G+1}$ using Background Char. & $\begin{array}{l}8.126 \\
(1.661)\end{array}$ & $\begin{array}{c}0.326 \\
(0.081)\end{array}$ & $\begin{array}{l}-0.002 \\
(0.006)\end{array}$ & 0.313 & -0.045 & 0.112 & 151 \\
\hline Including Married Individuals & $\begin{array}{l}7.904 \\
(1.462)\end{array}$ & $\begin{array}{c}0.298 \\
(0.072)\end{array}$ & $\begin{array}{l}-0.004 \\
(0.005)\end{array}$ & 0.277 & -0.074 & 0.091 & 194 \\
\hline Without Min. Consumption Adjustment & $\begin{array}{c}4.973 \\
(1.583)\end{array}$ & $\begin{array}{c}0.388 \\
(0.078)\end{array}$ & $\begin{array}{l}-0.003 \\
(0.005)\end{array}$ & 0.368 & -0.068 & 0.162 & 151 \\
\hline Conservative Measure of Durable Goods & $\begin{array}{l}8.142 \\
\text { (N.A.) }\end{array}$ & $\begin{array}{l}0.280 \\
\text { (N.A.) }\end{array}$ & $\begin{array}{l}-0.004 \\
\text { (N.A.) }\end{array}$ & 0.269 & -0.078 & 0.093 & 151 \\
\hline Non-Housing Consumption Value & $\begin{array}{c}4.814 \\
(1.646)\end{array}$ & $\begin{array}{c}0.277 \\
(0.081)\end{array}$ & $\begin{array}{l}-0.006 \\
(0.006)\end{array}$ & 0.243 & -0.117 & 0.077 & 151 \\
\hline
\end{tabular}

Notes: Post-college consumption is measured in $\$ 1,000$ s. The estimates of $\gamma_{w, 2}, \gamma_{d, 1}$, and $\gamma_{d, 2}$ are zero for all cases. The fourth and fifth columns report the respective averages of $\frac{\partial \tilde{C}\left(D_{G+1}, W_{G+1}\right)}{\partial W_{G+1}}$ and $\frac{\partial \tilde{C}\left(D_{G+1}, W_{G+1}\right)}{\partial D_{G+1}}$ across all observations in the post-college sample. Standard errors (in parentheses) are based on OLS estimation, reported only when those coefficient estimates are identical to the constrained least squares estimates; otherwise, N.A. is reported. 


\section{J Marginal Value of Increasing the Student Borrowing Limit}

Let $V_{G+1}\left(W_{G+1}, D_{G+1}\right)$ reflect the value function associated with an individual's post-college lifetime utility maximization problem at $t=G+1$ as given by equation (9) in the text. ${ }^{51}$ Then, the student's utility maximization problem at $t=1$ is given by:

$$
\begin{gathered}
V_{1}\left(W_{1} ; \bar{D}_{G+1}\right)=\max _{C_{1}, \ldots, C_{G}, D_{G+1}} E_{1}\left[\sum_{t=1}^{G} \beta^{t-1} U\left(C_{t}\right)+\beta^{G} V_{G+1}\left(W_{G+1}, D_{G+1}\right)\right] \\
\text { s.t. } \sum_{t=1}^{G} \frac{C_{t}}{(1+r)^{t-1}} \leq \sum_{t=1}^{G} \frac{W_{t}}{(1+r)^{t-1}}+\frac{D_{G+1}}{(1+r)^{G}}, \\
D_{G+1} \leq \bar{D}_{G+1},
\end{gathered}
$$

where $W_{t}$ reflects income in year $t$ (including any initial wealth in $W_{1}$ ).

Letting $\phi \geq 0$ and $\lambda_{G+1} \geq 0$ reflect the Lagrange multipliers on equations (14) and (15), respectively, the first order conditions for $C_{1}$ and $D_{G+1}$ are as follows:

$$
\begin{aligned}
C_{1} & : U^{\prime}\left(C_{1}\right)=\phi \\
D_{G+1} & : \beta^{G} E_{1}\left[\frac{\partial V_{G+1}\left(W_{G+1}, D_{G+1}\right)}{\partial D_{G+1}}\right]+(1+r)^{-G} \phi=\lambda_{G+1} .
\end{aligned}
$$

Based on the lifetime utility maximization problem at $t=G+1$,

$$
\frac{\partial V_{G+1}\left(W_{G+1}, D_{G+1}\right)}{\partial D_{G+1}}=-U^{\prime}\left(C_{G+1}\right) .
$$

Combining equations (16)-(18) yields the following consumption Euler equation:

$$
U^{\prime}\left(C_{1}\right)=[\beta(1+r)]^{G} E_{1}\left[U^{\prime}\left(C_{G+1}\right)\right]+(1+r)^{G} \lambda_{G+1}
$$

To determine the willingness-to-pay for an increase in the student borrowing limit, notice that the Envelope Conditions for the $t=1$ maximization problem above imply:

$$
\begin{aligned}
\frac{\partial V_{1}}{\partial W_{1}} & =\phi=U^{\prime}\left(C_{1}\right) \\
\frac{\partial V_{1}}{\partial \bar{D}_{G+1}} & =\lambda_{G+1}=\frac{U^{\prime}\left(C_{1}\right)-[\beta(1+r)]^{G} E_{1}\left[U^{\prime}\left(C_{G+1}\right)\right]}{(1+r)^{G}}
\end{aligned}
$$

\footnotetext{
${ }^{51}$ This period $G+1$ value function could come from other specifications of the post-college problem as long as $\partial V_{G+1}\left(W_{G+1}, D_{G+1}\right) / \partial D_{G+1}=-U^{\prime}\left(C_{G+1}\right)$.
} 
where the second equality in each case follows from equations (16) and (19), respectively. Hence, the amount of $W_{1}$ that a person is willing to give up to obtain one dollar increase in debt limit $\bar{D}_{G+1}$ is $\frac{\partial V_{1} / \partial \bar{D}_{G+1}}{\partial V_{1} / \partial W_{1}}=\frac{U^{\prime}\left(C_{1}\right)-[\beta(1+r)]^{G} E_{1} U^{\prime}\left(C_{G+1}\right)}{U^{\prime}\left(C_{1}\right)(1+r)^{G}}$.

Because one dollar increase in $\bar{D}_{G+1}$ corresponds to $(1+r)^{-G}$ dollar increase in current borrowing, the amount of income or wealth, $W_{1}$, that a student is willing to give up to increase borrowing during the first year of college by one dollar is $(1+r)^{G} \frac{\partial V_{1} / \partial \bar{D}_{G+1}}{\partial V_{1} / \partial W_{1}}=$ $\frac{U^{\prime}\left(C_{1}\right)-[\beta(1+r)]^{G} E_{1}\left[U^{\prime}\left(C_{G+1}\right)\right]}{U^{\prime}\left(C_{1}\right)}$. 